Int. J. Dev. Biol. 52: 683-701 (2008)

doi: $10.1387 / \mathrm{ijdb} .082580 \mathrm{jh}$

\title{
Anuran and pig egg zona pellucida glycoproteins in fertilization and early development
}

\author{
JERRY L. HEDRICK* \\ Department of Animal Science, University of California, Davis, CA, USA
}

\begin{abstract}
The envelope surrounding the eggs of all animals has many biological functions in fertilization and development. This review focuses on the anuran egg envelope in terms of its biochemistry, biophysics, structural biology and function in sperm-egg interactions and early development (embryo hatching). Egg envelopes from Xenopus laevis are among the most studied of the anurans, and are the central theme of this review. Comparisons of Xenopus laevis envelopes with those of other anurans and with pig egg envelopes are also included. This article presents historical as well as contemporary comparative perspectives on molecular and cellular mechanisms of sperm-egg envelope binding, block to polyspermy, envelope hardening, and hatching.
\end{abstract}

KEY WORDS: Xenopus laevis, pig, zona pellucida, fertilization, sperm binding, block to polyspermy

\section{Introduction}

\section{Previous reviews and the nature of this review}

This review focuses on anuran egg envelopes, their glycoprotein composition, chemistry, biophysics and structure, and the functional properties of the envelope. Emphasis will be on contributions from the author's laboratory with comparisons to other anuran and vertebrate systems where appropriate. In addition, a comparative approach to the structure and function of egg envelopes will involve a direct comparison of the Xenopus laevis and pig egg envelopes. This review will be selective rather than comprehensive. Other reviews encompassing the structures and functions of egg envelopes offer alternative perspectives (Iwao, 2000b; a; Katagiri, 1987; Watanabe and Onitake, 2002; Wong and Wessel, 2006).

\section{Discovery of anuran egg envelopes}

The original observation of sperm penetration and activation of amphibian eggs was made in a series of papers by Newport using the frog Rana temporaria, the toad Bufo vulgaris, and several urodele species (Newport, 1851; 1853; Newport and Ellis, 1854). Regarding anurans, Newport described the transport of eggs from the ovary to the oviduct, egg transit through the oviduct, and acquisition of jelly coats ('envelopes'). He experimentally demonstrated that jelly coats were required for fertilization, observed the penetration of sperm through the jelly layers and the egg envelope ('vitelline membrane'). He also observed the response of the egg to the fertilizing sperm i.e., egg activation, with the subsequent formation of the perivitelline space ('respiratory chamber'). New- port also noted that many sperm penetrating the jelly coat layers were stopped by the egg envelope. Newport's seminal observations on the surface reaction of the egg to sperm and the stoppage of sperm at the egg envelope were extended some 30 years later by Kupffer (Kupffer, 1882). In Bufo variabilis eggs, he observed sperm boring their way through the jelly coat but, after the fertilizing sperm made contact with the egg, surfaces changes took place that prevented further entrance of spermatozoa. Kupffer suggested the egg had established a 'defense' against extra sperm ["...a counter demonstration of the eggs against those spermatozoa that had not been able to enter" as described in (Morgan, 1897)]. Using contemporary nomenclature and the accumulated knowledge since that time of the fertilization process, Newport and Kupffer made the original observations of sperm penetration of the amphibian egg through the jelly coat layer, the vitelline envelope, and into the egg cell, the importance of the egg envelope in the fertilization process, the sperm induced release of cortical granule components into the perivitelline space (the cortical reaction), and establishment of a block to sperm penetration at the level of the egg envelope by components released from the egg. Both Newport and Kupffer suggested a possible connection between components released from the egg and the subsequent envelope block to sperm penetration. However, the effect of egg factors in altering the envelope architecture could not be experimentally demonstrated at that time since the

\footnotetext{
Abbreviations used in this paper: $\mathrm{CE}$, coelomic envelope; FE, fertilization envelope; VE, vitelline envelope; ZP, zona pellucida.
} 
architectural changes in the egg cortex and envelope induced by the fertilizing sperm were beyond the resolution limits of microscopes of-the-time and histochemistry was in its infancy in the mid $19^{\text {th }}$ century (Pearse, 1968). Refinement and extension of these original observations had to await the invention of the electron microscope and its biological application to gametes and fertilization in the mid $20^{\text {th }}$ century (Austin, 1968).

\section{Nomenclature}

Egg envelopes were independently observed by microscopists studying eggs from various species. Accordingly, different names were given to the same or related egg and embryo structures e.g., vitelline membrane for echinoderms, chorion for fish, zona radiata for amphibians, and zona pellucida for mammals (Anderson, 1974; Dumont and Brummett, 1985). We now know that these variously named extracellular structures play similar roles in fertilization and developmental processes and are composed of related and evolutionarily conserved glycoproteins. In this review, the term egg envelope, as previously used by others, will be used to describe the glycoproteinaceous extracellular matrix structure immediately adjacent to the egg membrane, (Anderson, 1974; Dumont and Brummett, 1985). From transmission and scanning electron microscopy studies, four forms of anuran egg envelopes were recognized, distinguishable by differences in their fine structures (for reviews see (Hedrick and Nishihara, 1991; Larabell and Chandler, 1989)).

Egg envelope biosynthesis begins early in oogenesis and is first visible at Stage II, appearing as unconnected patches of filamentous material accumulating between the oocyte plasma membrane and cumulus cells (Dumont, 1972). Glycoproteins continue to be deposited on the outer surface of the oocyte membrane until the patches coalesce, and at Stage IV, a fully assembled filamentous envelope can be observed, although permeated by villar processes from the cumulus cells and the oocyte. The egg envelopes isolated from ovarian oocytes are named ovarian envelopes or OEs. Prior to ovulation, the villar processes retract from the envelope, thereby giving the ovulated egg envelope a largely filamentous extracellular matrix and acellular fine structure. Eggs can be recovered from the body cavity or coelom of a female whose oviducts have been ligated (Hedrick and Hardy, 1991). Body cavity eggs cannot be fertilized as originally observed by Newport. Envelopes isolated from body cavity eggs are named coelomic envelopes or CEs. Body cavity eggs are swept into the oviduct by ciliary action, coated with jelly coat layers as eggs traverse the oviduct, stored in the ovisac for short periods and eventually spawned or oviposited. Jellied eggs can also be collected by physical manipulation of the gravid female. Oviposited eggs are fertilizable. Envelopes recovered after dejellying such eggs are named vitelline envelopes or VEs. Envelopes isolated after dejellying fertilized (or artificially activated) eggs and embryos are named fertilization envelopes or FEs. The fertilized egg cannot be 're-fertilized' by sperm. The FE has an outer amorphous layer termed the fertilization layer or $F$ layer and a filamentous 'VE-like' component termed the VE*. A thin, smooth layer of material in the perivitelline space separate from the FE was observed after fertilization using quick-freeze, deep-etch TEM analysis (Larabell and Chandler, 1988). However, its presence has not been confirmed by other methods nor has it been investigated further. In this review, I will focus on the
TABLE 1

\section{ZP GLYCOPROTEINS IN THE $X$. LAEVIS VE}

\begin{tabular}{cccccc} 
ZP glycoprotein & Apparent MW & Polypep. MW & Wt. \% & Mol \% & N-Glycos. Sites \\
\hline ZPB & $37 \mathrm{~K}$ & $36 \mathrm{~K}$ & 39 & 42 & 0 \\
ZPC & $41 \mathrm{~K}$ & $36 \mathrm{~K}$ & 43 & 47 & 2 \\
ZPA & $64 \mathrm{~K}+69 \mathrm{~K}$ & $53 \mathrm{~K}$ & 4.5 & 3 & 4 \\
ZPD & $80 \mathrm{~K}$ & $32 \mathrm{~K}$ & $<1$ & $<1$ & 8 \\
ZPX & & $83 \mathrm{~K}$ & & & 14 \\
ZPY & $112-120 \mathrm{~K}$ & $78 \mathrm{~K}$ & $(13)$ & $(7)$ & 16 \\
$(\mathrm{ZPZ} ?)$ & & $75 \mathrm{~K}$ & & & $?$ \\
\hline
\end{tabular}

CE, VE, and FE, their structures, glycoprotein compositions, and functions in fertilization and development.

Unfortunately, the nomenclature used to describe egg envelope glycoproteins is varied, confusing, and badly in need of unification. Investigators within the research areas of reproductive and gamete biology are frequently confounded by this problem and those outside these areas of research are perhaps discouraged, if not dissociated, from reading relevant publications. However, nomenclature problems in science are historically common. Envelope macromolecules separated by SDSPAGE were initially named according to the relative order of their SDS-PAGE electrophoretic mobilities, e.g., 1, 2, 3 or by their apparent molecular weights e.g., 55K, 65K. Currently, envelope macromolecules are agreed to be glycoproteins and are referred to as ZP glycoproteins without regard to the species from which the egg envelope was isolated. Regrettably, the nomenclature problem was not assisted by the initial success in cDNA cloning of ZP glycoproteins. The names initially used were specific to mouse envelope glycoproteins and were not comparable with envelope glycoproteins from different species. A universal nomenclature for ZP glycoproteins was proposed by Harris et al. (Harris et al., 1994). This was the first report to clone three ZP glycoprotein cDNAs from single organisms and to compare homologous ZP glycoprotein sequences in ten species. They proposed that the three ZP glycoproteins be named according to the size of the cDNAs with ZPA being the largest and ZPC the smallest. The biochemical or glycoprotein nomenclature problem has been further confused by gene nomenclature. Genes for the ZP glycoproteins have been named by individuals and committees apparently without regard to precedence, to contemporary and historical use, to names used in disciplines other than genetics e.g., gamete biology, biochemistry, or cell biology, and without sufficient regard to evolutionary relations i.e., not all ZP glycoprotein genes are present in humans or mice. A nomenclature based solely on human or mouse genes will necessarily be inadequate. Acknowledgement of the inadequacy of a ZP glycoprotein and gene nomenclatures and published appeals for a uniform nomenclature from researchers has often been made since the 1994 report of Harris et al. (Conner et al., 2005; Hedrick, 1996; Hughes, 2007; Spargo and Hope, 2003) However, since a nomenclature committee has not been formed by internationally recognized professional societies acting individually or collaboratively (as was done for instance in the case of chemical and biochemical nomenclatures), by journal editors collectively addressing the problem, or by investigators agreeing amongst themselves, the ZP glycoprotein nomenclature problem will remain troublesome. For this review, due to the discovery of larger and smaller ZP cDNAs, the author has slightly modified the 
original proposal of Harris et al., that ZP glycoproteins be named according to the sizes of their cDNAs. The alphabet has been considered circular rather linear, i.e., the last letter $\underline{z}$ has been placed next to first letter a thereby forming a circular arrangement of contiguous letters rather than a linear one. Accordingly, ZP glycoproteins with cDNAs increasingly larger than ZPA can be designated with increasing sizes as ZPZ, ZPY, ZPX, etc. and those with cDNAs smaller that ZPC can be designated with decreasing sizes as ZPD, ZPE, etc. A table equating the ZP glycoprotein nomenclature of Harris et al., with some ZP glycoprotein names has been published (Harris et al., 1994; Hedrick, 1996).

\section{The ZP glycoprotein composition of anuran egg enve- lopes}

\section{Isolation and biochemical composition}

The VE and FE from $X$. laevis eggs were the first envelopes isolated from any animal eggs (Wolf et al., 1976; Wyrick et al., 1974a). The $X$. laevis envelope isolation procedure employed classical or traditional subcellular fractionation methods, involving solubilization of the egg jelly by disulfide bond reduction, gentle homogenization of the dejellied eggs leaving the envelopes largely intact, sieving with small pore screens, and centrifugation procedures to separate and wash the envelopes from particulate and soluble cellular components (Hedrick and Hardy, 1991; Wolf et al., 1976). A major particulate contaminate, yolk granules, were solubilized using concentrated salt solutions followed by centrifugation to recover and wash the envelopes (Lindsay and Hedrick, 1989). The isolated envelopes retained their in situ fine structures. In the case of the VE, approximately $1 \mathrm{mg} / 1,000$ eggs of envelope glycoprotein was obtained with a 9:1 weight ratio of protein to carbohydrate. For FE, approximately 1.3 $\mathrm{mg} / 1,000$ eggs of envelope glycoprotein was obtained with an 8:1 ratio of protein to carbohydrate. The $F$ layer was readily removed from the FE by differential solubilization using Gal and EDTA which dissociated the lectin-ligand components of the F layer. The particulate $\mathrm{FE}$ envelope component, $\mathrm{VE}^{*}$, was recovered by centrifugation. Individual envelope ZP glycoproteins were separated and purified by preparative SDS-PAGE (Gerton et al., 1982). Envelopes from other anuran eggs have been isolated and characterized (Barisone et al., 2002; Caputo et al., 2005; Peavy and Carroll, 1993; Takamune et al., 1987), as well as the CE obtained from body cavity eggs after oviduct ligation (Grey et al., 1977). The methods used for $X$. laevis envelope preparation were applied in principle to isolation of the ZP from pig eggs (Dunbar et al., 1980). The biochemical composition of the envelopes was determined by SDS-PAGE. Most of the SDS-PAGE separated envelope macromolecules were shown to be glycoproteins based on staining methods and chemical analysis of isolated ZP glycoproteins. Molecular weight changes in ZPC when the CE is converted to the VE (Gerton and Hedrick, 1986a), in ZPA when the VE is converted to the FE (Gerton and Hedrick, 1986b), and the addition of the $\mathrm{F}$ layer (cortical granule lectin and jelly coat ligand) to the VE component of the FE (VE* ${ }^{\star}$ were detected using gel electrophoresis methods. The current composition of $X$. laevis egg envelopes is noted in Table 1. Most of these glycoproteins have homologues in other anuran egg envelopes, although differing in molecular weights due to different amino acid sequences and due to the extent, type and structures of glycans.

\section{cDNA cloning and protein domains}

The cDNAs from six $X$. laevis envelope glycoproteins have been cloned (Table 2). The ZPD glycoprotein has been found in birds (Okumura et al., 2004). The gp112-120 region of an SDSPAGE gel contains glycoproteins that are difficult to resolve. Deglycosylation of isolated glycoproteins from this region yielded three distinct protein bands with $\mathrm{MWs}$ of $83 \mathrm{~K}, 78 \mathrm{~K}$, and $75 \mathrm{~K}$, suggesting the presence of three different glycoproteins. ZPX (ZPAX) is one member of this group (83K). It is sequence related to ZPA and ZPB glycoproteins (Lindsay et al., 2001). ZPX has been found in fish (Kanamori, 2000). Another glycoprotein, designated ZPY, has been preliminary investigated. One other possible glycoprotein in this same region has yet to be investigated (ZPZ?). The protein moieties of ZP glycoproteins are evolutionarily conserved. ZPA, ZPB, and ZPC glycoproteins are homologues with egg envelope ZP glycoproteins from fish to mammals. ZP cDNA sequences from many organisms have been analyzed, compared, and evolutionary relations determined (Spargo and Hope, 2003). It is beyond the scope of this review to discuss evolutionary aspects of ZP glycoproteins and the structures of ZP genes.

ZP glycoproteins possess conserved domains which relate to their cellular processing and extracellular functions (Fig. 1). ZP glycoproteins are biosynthesized via the endoplasmic reticulum and the Golgi and extracellularly secreted by insertion in the plasma membrane with subsequent proteolytic processing. Accordingly, the protein moieties of ZP glycoproteins contain signal sequences, transmembrane domains, furin cleavage sites, and are glycosylated. ZPB glycoproteins contain a trefoil or P-type domain. Trefoil domains (at least 268 domains in 166 proteins) are composed of 45 amino acid residues with 3 disulfide bonds and are found in secreted eukaryotic proteins. The function of the domain is unknown. All ZP glycoproteins contain ZP domains

TABLE 2

CLONED ZP GLYCOPROTEINS IN ANURANS

\begin{tabular}{|c|c|c|c|c|c|c|}
\hline \multirow[b]{2}{*}{ Species } & \multicolumn{6}{|c|}{ Accession Number } \\
\hline & ZPA & ZPX & ZPB & ZPC & ZPD & ZPY \\
\hline$X$. laevis & AF038151 & AF225906 & XLU44950 & XLU44952 NM_001087917 & U44949 & $\begin{array}{l}\text { AY937405 } \\
\text { AY937406 }\end{array}$ \\
\hline X. tropicalis & AY079191 & AY079195 & AY079192 & AY079193 & NM_203521 & \\
\hline D. pictus & AAK84067 & & & & & \\
\hline B. arenarum & DQ394072 & & DQ403815 & AY185123 & & \\
\hline
\end{tabular}


located close to the C-terminus. ZP domains (at least 690 domains in 683 proteins) are broadly distributed in extracellular proteins and glycoproteins from nematodes to mammals. It was first suggested for tectorins that the ZP domain may function as a conserved binding module for protein polymerization and formation of filaments (Killick et al., 1995; Legan et al., 1997). Experimental evidence for this domain polymerization function was established for ZP glycoprotein filament formation (Jovine et al., 2002). Sequence analysis of ZP domains suggested the presence of two regions in the $\mathrm{ZP}$ domain, the $\mathrm{N}$ - and $\mathrm{C}$-subdomains (ZP-N and ZP-C). The ZP-N subdomain was proposed as mainly responsible for the heteropolymerization of $Z \mathrm{P}$ glycoproteins and formation of envelope filaments (for reviews, see (Jovine et al., 2005; Monne et al., 2006)). From sequence analysis, the $\mathrm{N}$ terminal region of $\mathrm{ZP}$ glycoproteins were proposed to have conserved residues related to the $\mathrm{ZP}-\mathrm{N}$ subdomain of the $\mathrm{ZP}$ domain (Callebaut et al., 2007). These ZP-N subdomains were present in single or multiple copies in various ZP glycoproteins. It was speculated the $\mathrm{N}$-terminal region subdomains might be involved in the ZP glycoprotein heteropolymerization process and in the biological roles of ZP glycoproteins. Experimental evidence supporting this speculation has yet to be published.

\section{Oligosaccharides}

The N-linked oligosaccharide moieties of VE ZP glycoproteins were composed of high mannose (Man5-9) and mostly neutral bi, tri- and tetra-antennary complex glycans (Vo et al., 2003). The glycans were primarily derived from ZPC. As will be discussed later, one of the neutral complex glycans of ZPC was involved in sperm binding. ZPA N-linked glycans were of the high mannose and acidic complex types. ZPB had no N-linked glycans, consistent with the lack of $\mathrm{N}$-glycosylation sites in the ZPB protein moiety. ZPX possessed only high mannose N-linked glycans. Due to the small amount of ZPD that can be isolated, its glycans have not been investigated. A single $O$-linked trisaccharide structure was found by analysis of VE, VE* (derived from FE), ZPB, ZPC and ZPC* isolated from the VE*, namely GalNAc- $\beta-G a l-\beta$ GalNAc. This O-linked oligosaccharide structure apparently does not play any functional role in sperm binding to the VE, block to polyspermy, or hardening of the FE. The location of $\mathrm{N}$-linked

\section{TABLE 3}

BIOPHYSICAL PROPERTIES OF $X$. LAEVIS ENVELOPES REFLECTIVE OF CONFORMATIONAL DIFFERENCES IN ZP GLYCOPROTEINS ${ }^{1}$

\begin{tabular}{|c|c|c|c|}
\hline & CE & VE & FE \\
\hline Accessibility of Tyr Residues & + & - & - \\
\hline \multicolumn{4}{|l|}{ Binding } \\
\hline Hydrophobic - ANS $^{2}$ Affinity & 1 & 0.14 & 0.086 \\
\hline - ANS Stoichiometry & 1 & 1.2 & 1.5 \\
\hline Ferritin Stoichiometry ${ }^{3}$ & 1 & 0.21 & 0.15 \\
\hline Symmetry - F layer & $?$ & + & - \\
\hline Deformability $^{4}$ & 1 & 1.9 & 0.11 \\
\hline Melting Temperature ${ }^{5}$ & 51 & 42 & 56 \\
\hline Sensitivity - Trypsin Proteolysis & $?$ & + & - \\
\hline
\end{tabular}

Abbreviations: $\mathrm{CE}$, coelomic envelope; FE, fertilization envelope; VE, vitelline envelope.

1. Table adapted from (Hedrick and Nishihara, 1991). Numerical values are expressed relative to those of CE except for melting temperatures. 2. ANS = aminonaphthalenesulfonic acid. ANS relative affinities are based on $\mathrm{K}_{\mathrm{A}}$ values. 3 . Based on $\mu \mathrm{g}$ ferritin bound $/ \mathrm{mg}$ of envelope protein. 4. Measured units $=\mu \mathrm{m} / 10^{2}$ dynes $/ \mathrm{cm}^{2}$. 5. Measured units $={ }^{\circ} \mathrm{C}$. glycans and $\mathrm{N}$ sequons in the $X$. laevis ZP glycoproteins is shown in Fig. 1.

\section{Site of biosynthesis}

Based on immunocytochemical localization studies using antibodies against the VE, ZPC, and ZPA, the oocyte is apparently the site of ZP glycoprotein biosynthesis (Yamaguchi et al., 1989). In addition, Northern blotting and in situhybridization experiments performed with cDNAs from ZPA, ZPB, ZPC, and ZPX identified the oocyte as the biosynthetic site of ZP glycoproteins (Kubo et al., 1997; Kubo et al., 2000; Lindsay et al., 2001; Tian et al., 1996; Yang and Hedrick, 1997).

\section{Biophysics of anuran egg envelopes}

\section{Glycoprotein constituents interact to form the egg envelope via non-covalent bonds}

Isolated envelopes are physically stable and do not readily dissolve in aqueous media under conditions simulating that found in the frog's spawning environment e.g., conditions such as $\mathrm{pH}$, salt concentrations, ions present, temperature. Each envelope form however, had different solubility properties (Bakos et al., 1990a; Wolf et al., 1976). In general, the VE was more easily dissolved than the FE. For instance, the VE dissolved slowly in water or solutions buffered near $\mathrm{pH} 7$ or in $0.045 \mathrm{M}$ mercaptoethanol solutions, $\mathrm{pH} 8$, or moderate temperatures e.g., $42^{\circ} \mathrm{C}$. The FE did not dissolve under these conditions, but could be dissolved in aqueous solutions containing detergents e.g., SDS, denaturants such as guanidine hydrochloride or urea, at higher temperatures e.g., $56^{\circ} \mathrm{C}$, and extremes of $\mathrm{pH}$ such as $0.1 \mathrm{M} \mathrm{NaOH}$. In general, solubility was increased with an increase in $\mathrm{pH}$ and temperature and decreased with ionic strength. These solubility conditions are compatible with the disruption of non-covalent interactions between the ZP glycoproteins, and therefore, the structural integrity of the egg envelope is dependent on noncovalent interactions. The dissolution process, in contrast to the dissociation process caused by chaotropic agents, produced soluble aggregates of ZP glycoproteins with MWs of greater than $10^{6}$ (Nishihara et al., 1983). The conformations of glycoproteins in the soluble aggregate form of the envelope are like that of the intact envelope, as will be discussed later. The envelope ZP glycoproteins can be dissociated into separate macromolecues by disruption of intermolecular non-covalent interactions with chaotropic agents. Reduction of intramolecular disulfide bonds in ZP glycoproteins assists the process of dissociation, but is not required (there are no intermolecular disulfide bonds). The biophysics of envelope behavior is that of a "unified polycomponent system in which the states of all elements (glycoproteins) is mutually connected" (Bakos et al., 1990a). Thus, interaction of individual ZP glycoproteins to form aggregates, assembly of macromolecular aggregates into higher order structures such as filaments, and organization of filaments into the overall architecture of the envelope are due to non-covalent interactions.

\section{ZP glycoproteins have different conformations in CE, VE, and $F E$}

Although all envelope forms can be characterized in common as polycomponent interacting systems, they have distinctly different physicochemical properties. This is perhaps most readily 
demonstrated by the distinct morphological forms of envelopes as visualized with transmission and scanning electron microscopy [X. laevis (Hedrick and Nishihara, 1991; Larabell and Chandler, 1989); L. laevis (Peavy and Carroll, 1993); B. arenarum(Mariano and Cabada, 1978; Mariano et al., 1984); B. japoncius(Katagiri et al., 1982); D. pictus(Campanella etal., 1992; Caputo etal., 2001); R. japonica (Yoshizaki and Katagiri, 1981)]. The ZP glycoproteins are organized into filaments and filament arrangements are distinguishable in the CE, VE, and FE. These envelope macrostructures visualized by electron microscopy likely reflect differences in the conformations of the constituent ZP glycoproteins. Conformational differences were first observed in radioiodination studies of envelopes where the preglycoprotein form of ZPC (gp43) was labeled in the CE but was not labeled in VE (Nishihara et al., 1983). After dissociation of the VE with detergents or chaotropic agents, ZPC was readily labeled. This result was interpreted as reflecting glycoprotein conformational differences in different forms of the envelopes. As will be discussed later, these ZPC conformation differences are also reflected in ZPC ligand functions for sperm binding.

Additional studies of the physical properties of the envelopes supported this interpretation (Table 3) (Bakos et al., 1990a). The temperature dependent solubilization curves of CE, VE, and FE were steeply sigmoidal, symmetrical, and possessed a single inflection point, defined as $\mathrm{T}_{\mathrm{m}}$ (the temperature at which the transition from the solid to solution state was $50 \%$ complete). Thus, the transition from the insoluble to the soluble state is a highly cooperative one regarding interaction of the component glycoproteins. The CE had more exposed hydrophobic sites that the VE and FE from its greater binding of the hydrophobic dye, 1-anilino-8-naphthalenesulfonic acid. The CE also had a greater exposure of ferritin binding sites than the VE or FE. Deformability or flexibility measurements established that the FE was 9-16 times stiffer or less flexible to deformation than the CE or VE. The greater stiffness of the FE relative to the VE is in conformity with the concept of envelope hardening at fertilization. Taken together, these results support the interpretation that ZP glycoproteins have substantially different conformations in the three envelope forms.

\section{Biophysical changes in envelopes are caused by proteases and a glycanase}

Reduction in the molecular weight of ZPC (preglycoprotein to glycoprotein) when the egg traverses the oviduct and undergoes the CE to VE conversion was first observed in $X$. laevis (Gerton and Hedrick, 1986a). This change was shown to be due to hydrolysis of an Arg peptide bond in the Nterminal region of ZPC caused by a secreted serine active site protease from the pars recta region of the oviduct, named oviductin (EC 3.4.21.120). In a series of papers, the enzyme was shown to be secreted by the oviduct, was biochemically isolated and characterized as a glycoprotein, was characterized as a Ser active site protease and its peptide bond specificity determined, was demonstrated to hydrolyze ZPC and caused the conversion of CE to VE, and was cloned (Bakos et al., 1990b; Hardy and Hedrick, 1992; Lindsay et al., 1999a). Oviductin is biosynthesized as a mosaic protease with two Ser active-site protease domains and 3 CUB domains (Fig. 2). The first observation of a trypsin-like activity in a pars recta oviduct extract was from B. arenarum (Miceli et al., 1978). Trypsin inhibitors and ConA inhibited the action of a pars recta extract on $B$. arenarum eggs (Raisman et al., 1977). These observations were likely due to a $B$. arenarumoviductin, although oviductin has not yet been isolated to homogeneity from this species. On the other hand, oviductin has also been isolated and cloned from $B$. japonicas and shown to be homologous with the $X$. laevisenzyme (Hiyoshi et al., 2002; Takamune and Katagiri, 1987). Using heterologous combinations of pars recta oviduct extracts containing oviductin enzymes, and CEs containing ZPC preglycoprotein substrates, the potential species specificity of the proteolytic process was tested (Takamune et al., 1987). The oviductin proteolytic activity was not species specific, as the $B$. japonicus enzyme specifically hydrolyzed $X$. laevis ZPC preglycoprotein, and vice versa. This lack of species specificity at the enzyme-
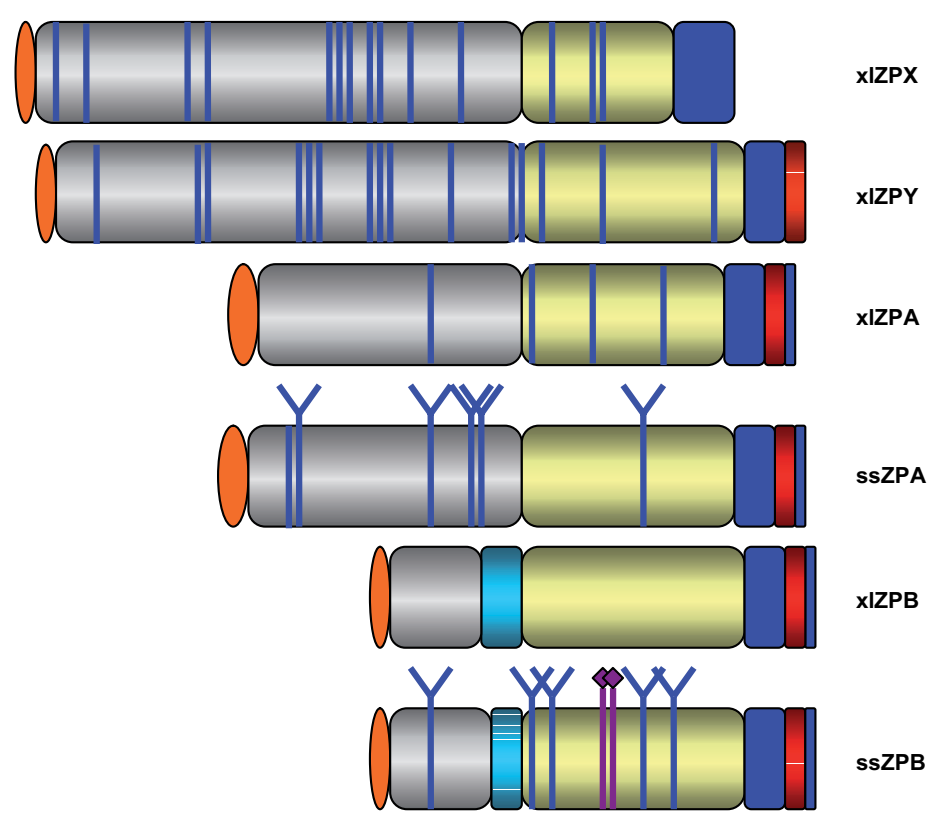

xIZPB
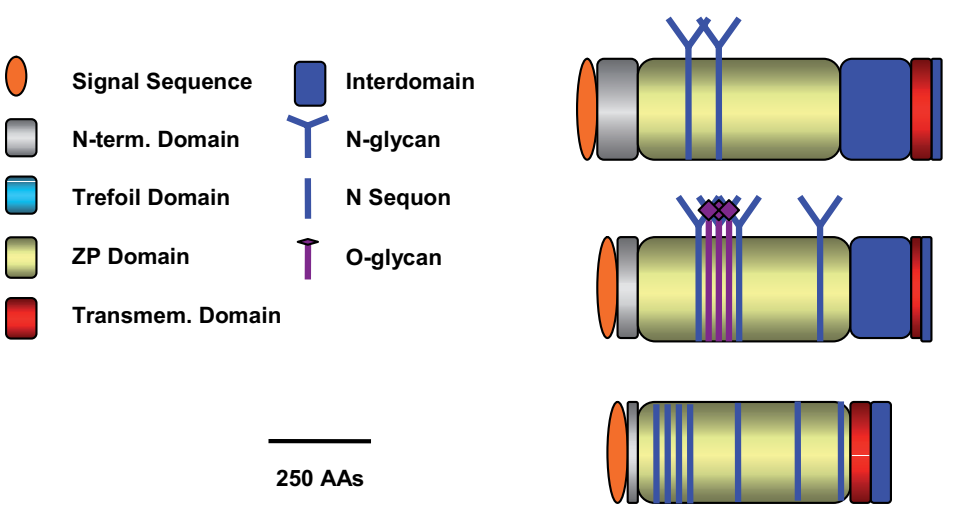

xIZPD
Fig. 1. ZP Glycoprotein Domains. The domain widths are approximately to scale with the amino acid sequence lengths. Abbreviations are $\mathrm{XI}, \mathrm{X}$. laevis; Ss, Sous scrofa. 
substrate level was not surprising since the limited hydrolysis of only a single type of peptide bond (Arg) in the $\mathrm{N}$-terminal domain is involved in this reaction and the enzymes and the substrates are homologous in structure. However, treatment of $B$. japonicus coelomic eggs with $X$. laevis pars recta extracts did not render eggs fertilizable with $B$. japonicus sperm, whereas treatment with $B$. japonicus extract rendered eggs fertilizable. Thus, oviductin and the ZPC preglycoproteins in these species were evolutionarily conserved and ZPC preglycoprotein hydrolysis is apparently essential, but not sufficient for making eggs fertilizable. Perhaps other fertilization important factors, such as jelly glycoproteins or other oviductal secretions, were missing (Miceli et al., 1987). Similar experiments were performed with coelomic eggs and pars recta extracts from $B$. arenarumand $L$. chaquenis (Whitacre et al., 1996). Treatment of eggs with heterologous extracts did not result in fertilizable eggs. In this case, the authors believed that the proteases and proteolytic activities in the pars recta extracts were not evolutionarily conserved. However, proteolysis of the ZPC preglycoprotein was not determined. It has been observed that pancreatic trypsin, a general protease with peptide bond specificity for Arg and Lys residues, mimicked the action of oviductin on coelomic eggs. Trypsin and clostripain specifically hydrolyzed only ZPC preglycoprotein and rendered coelomic eggs fertilizable (Hardy and Hedrick, 1992; Llanos et al., 2006). The suggestion was made that oviductin processing of ZPC occurs at both the $\mathrm{N}$ -
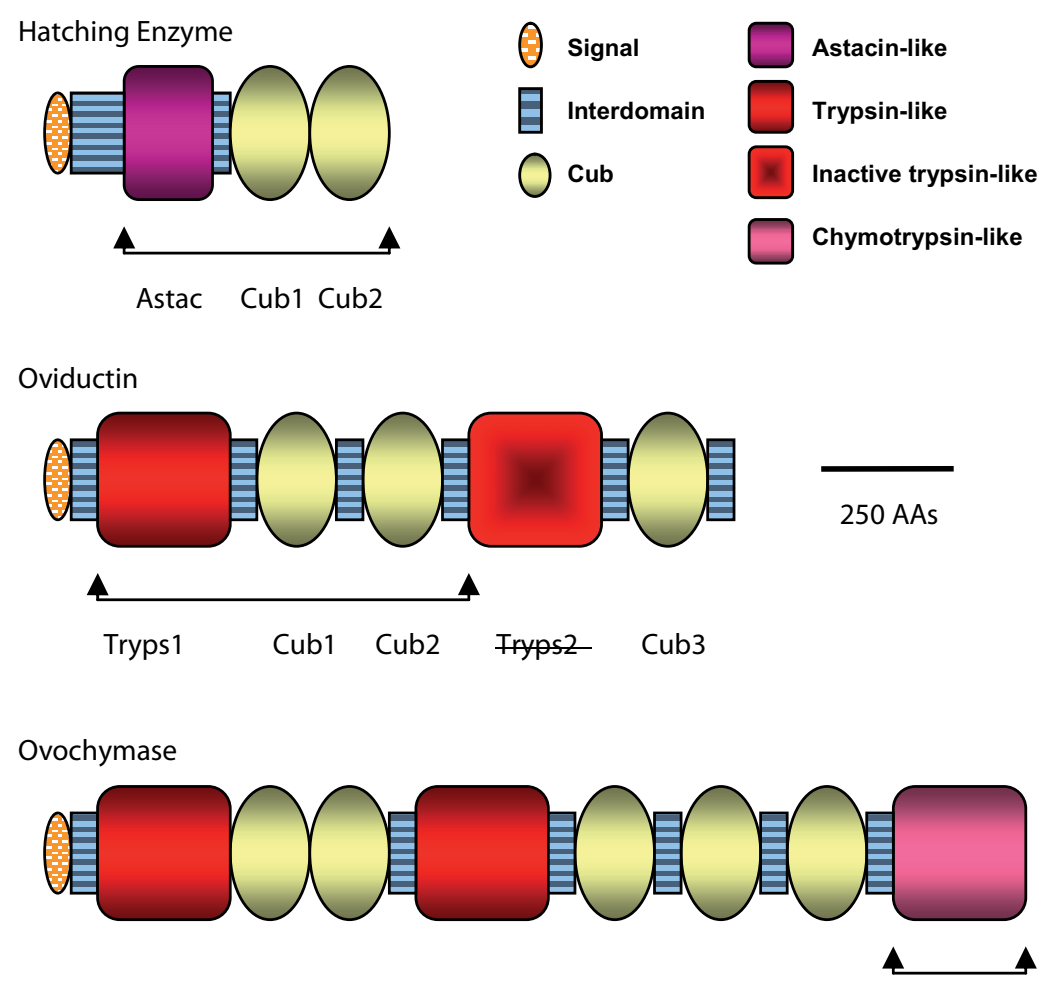

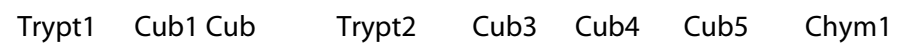

Fig. 2. ZP Proteases - Domain Structures. The domain widths are approximately to scale with the amino acid sequence lengths. The processed protease is delimited by the arrowheads. and C-terminal ends of the glycoproteins, as the Gly-Ser-Arg cleavage site for specific hydrolysis is present at both $\mathrm{Arg}_{61}$ and $\mathrm{Arg}_{373}$ (Kubo et al., 1999). The molecular and biological significance of processing at the $\mathrm{C}$-terminus is unknown.

As will be discussed later, $X$. laevis ZPC is the key envelope glycoprotein that functions as a ligand for sperm binding to the egg envelope (Vo and Hedrick, 2000). Although ZPC preglycoprotein is present in the CE form of the egg envelope, ligand sites are conformationally unavailable to the sperm surface, and hence, sperm do not bind to the coelomic egg. The specific hydrolysis of ZPC preglycoprotein by oviductin causes conformational changes in the ZPC glycoprotein resulting in the exposure of sperm binding sites in the egg envelope. Thus, biophysical changes in the egg envelope and conversion of the CE to the VE as the egg traverses the oviduct are caused by the limited proteolysis of ZPC by oviductin.

It was first observed in $X$. laevis that a reduction in the molecular weight of an envelope glycoprotein occurred when the VE was converted to the FE (Gerton and Hedrick, 1986b). Two glycoproteins decreased in MWs $(69 \mathrm{~K}, 64 \mathrm{~K} \rightarrow 66 \mathrm{~K}, 61 \mathrm{~K})$ due to limited proteolysis. The $69 \mathrm{~K}$ and $64 \mathrm{~K}$ components (ZPA) were shown to be isomers due to different glycosylation states of the same protein backbone. Therefore proteolysis of a single peptide bond occurred in the two different isoforms. ZPA proteolysis occurs at $A_{s p_{156}}$ and generates a 27 amino acid peptide that remains disulfide bonded to the glycoprotein component (Tian et al., 1999). Proteolytic activities released in the cortical reaction and separated by SDS-PAGE were associated with $30 \mathrm{~K}$ and $45 \mathrm{~K}$ proteins (Lindsay and Hedrick, 1989). The 45K protease has not been characterized. The $30 \mathrm{~K}$ enzyme was isolated and shown to be chymotrypsin-like in its enzymatic properties and named ovochymase (Lindsay and Hedrick, 1995). More recently, a third protease was partially purified from cortical granule exudates, identified as a metalloprotease, and specifically hydrolyzed ZPA (Lindsay and Hedrick, 2004). The ZPA hydrolytic event is likely to be the triggering mechanism inducing global conformational changes of VE glycoproteins. Protease associated changes in ZP glycoproteins (ZPA?) of the $B$. arenarum VE have been reported (Oterino et al., 2006).

$\mathrm{N}$-acetyl- $\beta$-D-glucosaminidase activity contained in cortical granules was first described in $X$. laevis eggs (Greve et al., 1985). The glucosaminidase activity was released into the perivitelline space in the cortical reaction. Treatment of oviposited eggs with glucosaminidase activity rendered eggs unfertilizable. More recently, glucosaminidase released in the egg cortical reaction was shown to hydrolyze a specific ZPC oligosaccharide moiety (Vo et al., 2003). Hydrolysis of a specific ZPC non-reducing terminal $\mathrm{N}$-acetyl glucosamine residue destroyed the sperm ligand activity of ZPC as will be discussed later. However, it is not known if this specific and limited glycan hydrolysis contributes to the biophysical changes in the egg envelope when the VE is converted to the FE.

Conversion of the VE to the FE was originally identified by the appearance of a new layer on the outer 
aspect of the egg envelope, termed the fertilization or F layer (Grey etal., 1972). The molecular basis for formation of the F layer was shown to be due to a $\mathrm{Ca}^{2+}$ mediated binding of a cortical granule lectin to its ligand located in the innermost layer of the jelly coat, thereby forming a lectin-ligand heteropolymer (Wyrick et al., 1974b). The F layer functions as a block to polyspermy. However, it is unknown if the presence of the $F$ layer contributes to biophysical differences observed in VE and FE. The F layer can be dissolved and dissociated from the FE by galactose and/or EDTA and the resulting envelope component, VE* , separated by centrifugation. In recombination experiments, binding of the lectin-ligand complex to the envelope surfaces was observed to be different in the VE versus VE*. The F layer bound to both the inner and outer surface of the VE but bound only to the outer surface of the VE*, its 'natural' location in the FE (Hedrick and Nishihara, 1991). Two possible explanations were proposed to explain this difference. 1) $\mathrm{F}$ layer binding to the inner and outer VE surfaces involved different ZP glycoproteins which were differentially distributed in the envelope. ZP glycoproteins on the innermost surface were modified or destroyed during the cortical reaction while those on the outermost surface were unchanged. 2) F layer binding to the VE surfaces involved a single glycoprotein equally distributed in the envelope. Binding to the F layer by glycoproteins on the outer surface protected them from modification by factors released in the cortical reaction. $F$ layer binding to envelope components could also prevent localized or surface conformational changes in ZP glycoproteins, thereby protecting them from destruction by components released in the cortical reaction. Identification of the macromolecules involved in F layer-ZP glycoprotein binding remains unknown as does the mechanism of $F$ layer binding to the VE, but it seems that the $F$ layer does not substantially contribute to the biophysical differences observed in the envelope glycoproteins.

Thus, the biophysical changes in the VE and FE reflect conformational changes in ZP glycoproteins. These changes are induced by the limited proteolysis of ZPA caused by a cortical granule protease. Hydrolysis of $\mathrm{N}$-acetyl glucosamine residues on ZPC oligosaccharides or formation of the $\mathrm{F}$ layer by a cortical granule lectin binding to a jelly coat ligand do not appear to be major contributors to the biophysical differences observed in the VE and FE.

\section{Functions of anuran egg envelopes and structural correlates}

\section{Sperm binding}

As stated earlier, Newport observed that eggs recovered from the coelom or body cavity of female frogs cannot be fertilized (Newport, 1851). In 1962, more than 100 years after Newport's observations, it was still uncertain as to the exact reasons for the lack of coelomic egg fertilizability, although attention had been focused on the oviductally secreted jelly coats and on changes in the egg itself (Rugh, 1962). We now know that egg jelly glycoproteins and chemical modifications of the envelope are required by sperm to bind and penetrate the VE and to fuse with the egg membrane. Although all the molecules involved in this process, and the molecular and cellular mechanisms of this jelly coat requirement have yet to be completely determined, it seems likely the jelly coat requirement relates to sperm capacitation and/or induction of the acrosome reaction (Ueda et al., 2002; Wolf and Hedrick, 1971; Yurewicz et al., 1975).

Required changes in the egg envelope glycoproteins for fertilization and sperm binding are now defined. Sperm do not bind or penetrate the $C E$, readily bind to and penetrate the VE, and do not bind or penetrate the FE (Grey et al., 1976; 1977). Changes in the egg envelope from a non-binding non-penetrable state, to a binding and penetrable state, and then to a non-binding and nonpenetrable state are caused by molecular modifications of ZP glycoproteins.

In the VE, using isolated $X$. laevis ZP glycoproteins and a direct sperm binding assay, the major glycoprotein functioning as a ligand for sperm surface receptors was ZPC (Vo and Hedrick, 2000). On a molar composition basis approximately, $85 \%$ of the ligand activity of the VE was associated with ZPC; ZPA possessed $6 \%$ of the ligand activity. However, ligand activity also involved a synergistic interaction between ZP glycoproteins as the sum of sperm binding to isolated individual glycoproteins was less than that of the solubilized VE. When ZPA, ZPB, and ZPC were proportionally combined, sperm binding was equal to that of the soluble VE whereas other combinations of ZP glycoproteins were less effective. In contrast, using isolated $X$. laevis ZP glycoproteins and an indirect or competitive assay for sperm binding, a major role for ZPA as the ligand for sperm binding was proposed by Tian et al. (Tian et al., 1997). In B. japonicus and $B$. arenarum, ZPC was identified as the major envelope glycoprotein functioning as a ligand for sperm binding (Barisone et al., 2007; Omata and Katagiri, 1996). In D. pictus, binding to a $75 K$ VE glycoprotein, a presumed ZPC glycoprotein equivalent, was reported (Caputo et al., 2005).

Although sperm do not bind to the isolated particulate CE or to the coelomic egg, sperm bind to the solubilized CE. The CE contains an 'immature form' or preglycoprotein form of ZPC (gp43) which is converted to a 'mature' form of ZPC (gp41) by the oviductal enzyme oviductin. Thus, proteolytic processing of ZPC unmasks existent ligand binding sites via conformational changes when the CE is converted to the VE in the oviduct (Vo and Hedrick, 2000). The complex N-linked glycans of ZPC are involved in sperm binding. One neutral bi-antennary complex $\mathrm{N}$-glycan structure possessed a terminal $\beta-\mathrm{N}$-acetylglucosamine residue. Removal of this hexoseamine residue resulted in a loss of sperm binding. Thus, sperm binding involves: 1) ZPC as the predominant ligand, 2) a synergistic interaction between ZPC and other ZP glycoproteins, 3) particular conformations of ZP glycoprotein complexes, and 4) ZPC N-linked complex glycans possessing terminal $\beta$ - $\mathrm{N}$-acetylglucosaminidase residues.

Sperm do not bind or penetrate the FE neither the $F$ layer, or the inner egg-plasma-membrane facing surface of VE* (Grey et al., 1976). Presumably the outer surface ligands for sperm binding are not accessible due to the presence of the $\mathrm{F}$ layer or the ligands on the outer and inner surfaces have been chemically modified or a combination of these two possibilities as discussed earlier for $F$ layer binding to VE and VE* ZPC $\left(\mathrm{ZPC}^{*}\right)$ isolated from FEs is not a ligand for sperm binding. Two enzyme catalyzed modifications of ZP glycoproteins are known to occur in the VE to FE transition. As mentioned previously, cortical granule $\beta-\mathrm{N}$ acetylglucosaminidase is released in the cortical reaction and removes terminal $\beta-\mathrm{N}$-acetylglucosamine residues from ZPC Nlinked glycans that are essential for sperm binding. It seems likely 
this hydrolytic reaction would occur throughout the envelope, including both the inner and outer surfaces. Thus, both envelope surfaces would no longer bind sperm if this essential sugar residue were missing. In addition, N-terminal proteolysis of ZPA is caused by a metalloprotease (Lindsay and Hedrick, 2004). The ZPA protease is likely released from the cortical granules in the cortical reaction as mentioned previously. It was proposed by others that ZPA is a sperm ligand and proteolysis chemically destroys its ligand properties (Tian et al., 1996). However, our results suggest that ZPA proteolysis is responsible for massive conformational changes in the envelope glycoproteins. Such conformational changes may 'mask' sperm ligand sites on ZPC that have not been modified by glucosaminidase action. This masking process may be analogous in reverse to the CE to VE unmasking of ZPC sperm binding sites caused by oviductin proteolysis of ZPC. In summary, the loss of sperm binding when the VE is converted to the FE involves: 1) formation of the F layer by a cortical granule lectin and a jelly coat ligand, 2) release of terminal $\beta$-N-acetylglucosamine residues from ZPC N-linked glycans, 3) proteolysis of ZPA resulting in conformational changes of ZP glycoproteins, effectively hardening the envelope and masking ZPC N-linked glycan ligands.

\section{Sperm acrosome reaction and penetration}

Anuran amphibians may be the most primitive order having sperm acrosome reactions similar to those occurring in sperm from various mammalian orders (Ueda etal., 2007). The acrosome reaction in most anuran sperm apparently takes place after binding to the VE (Ueda et al., 2002). However, in D. pictus, the acrosome reaction takes place in the jelly coat layers (Campanella et al., 1997). In X. laevis, B. japonicus, $B$. arenarum, and $L$. chaquensis the majority of sperm bound to the VE have intact acrosomes (Martinez and Cabada, 1996; Raisman et al., 1980; Ueda et al., 2003; Yoshizaki and Katagiri, 1982). Thus, nonenvelope factors are responsible for induction of the acrosome reaction. $X$. laevis sperm bound to the VE were induced to undergo the acrosome reaction by a large molecular weight glycoprotein derived from the pars recta oviduct and termed ARISX (Ueda et al., 2003). Using various plant lectins to inhibit the ARISX induced acrosome reaction, terminal $\alpha-D$-GalNAc residues were essential to ARISX activity (Ueda et al., 2007). ARISX present in crude extracts induced the acrosome reaction in other amphibian sperm and hence, the activity was not species specific. Purification, structural characterization, and cloning of ARISX and relation to its acrosome reaction inducing activity are critically important to understanding the mechanisms of the acrosome reaction in anuran sperm.

Sperm penetration of the anuran egg envelope has long been associated with sperm proteases or so-called sperm lysins (for references see (Iwao and Katagiri, 1982; Yamasaki et al., 1988)). Proteolytic activity of sperm extracts on various protein substrates, including the VE, has been reported in several species. Based on inhibitors studies, proteolytic activity was considered to be associated with Ser active site proteases. A 32,000 MW protease from sperm of $B$. japonicus was partially purified and its enzymatic properties characterized (Iwao and Katagiri, 1982; Yamasaki etal., 1988). The enzyme preferentially hydrolyzed Arg containing synthetic substrates, had a pH optimum of 7.0-7.6, and was inhibited by trypsin inhibitors. The activity was released from sperm by pars recta extracts presumably via the sperm acrosome reaction. Peptide substrates inhibited fertilization. Thus, there is evidence that a sperm protease is involved in the envelope penetration process, but its isolation to homogeneity and characterization regarding hydrolytic action on ZP glycoproteins, and its mechanism in assisting sperm penetration of the VE has yet to be determined.

\section{Blocks to polyspermy, hardening, and elevation of the enve- lope}

Fertilization in anurans is monospermic. Blocks to polyspermy occur at the level of the egg envelope and the egg membrane. Three molecular mechanisms involving the egg envelope are apparently involved in this critically important biological process.

Treatment of ovipositied $X$. laevis eggs with $\beta-\mathrm{N}$ acetylglucosaminidase rendered them unfertilizable (Prody et al., 1983). $\beta$-N-acetylglucosaminidase activity was released in the cortical reaction triggered by the fertilizing sperm. As discussed previously, this enzyme activity removes $\mathrm{N}$-acetyl glucosamine residues from ZPC glycans that are essential for sperm binding to the VE (Vo et al., 2003). Thus, a molecular mechanism for establishing a block to polyspermy is hydrolysis of ZP glycans serving as ligands for sperm binding.

Initially, two major proteolytic activities were detected in the cortical granule exudate from $X$. laeviseggs (Lindsay and Hedrick, 1989). A trypsin-like activity was associated with a $45 \mathrm{~K} \mathrm{MW}$ protease and a chymotrypsin-like activity with a $30 \mathrm{~K} \mathrm{MW}$ protease, ovochymase. The $45 \mathrm{~K}$ protease has not been further characterized. Ovochymase is apparently immobilized in the perivitelline space in fertilized and unfertilized eggs (Lindsay et al., 1992). Ovochymase is translated as a part of a polyprotease complex (Fig. 2). Ovochymase was the first described secreted polyprotease. Polyproteases are now known to be present in humans (Cal et al., 2007). The ovochymase polyprotease contained three Ser active site protease domains. Ovochymase was C-terminally located to two trypsin-like protease domains, named ovotryptase 1 and ovotryptase 2 (Lindsay et al., 1999b). The three protease domains were separated by a total of 5 CUB domains. Immunocytochemical studies localized all three protease domains to the cell surface or perivitelline space in unactivated eggs. Activated eggs exhibited less staining for ovochymase and ovotryptase1. However, isolated ovochymase did not cause hydrolysis of ZPA. Although ovotryptases are present on the egg surface before and after fertilization, the extracellular matrix substrates for these enzymes and the enzyme's biological functions remain to be discovered. An ovochymase gene has been detected in humans but the role of the gene is unknown (personal communication, J. Woods).

A third proteolytic activity associated with the $X$. laevis egg surface was more recently described. AZPA protease was isolated from the exudate of activated eggs (Lindsay and Hedrick, 2004). The protease had the properties of a $\mathrm{NaCl}$-sensitive zinc metalloprotease with enzymatic properties similar to bone morphogenetic protein 1, BMP-1. The enzyme converted the VE form of ZPA $(69 \mathrm{~K} \& 64 \mathrm{~K})$ to the FE form $(66 \mathrm{~K} \& 61 \mathrm{~K})$ and caused hardening of the envelope. Based on specific inhibitor results of the ZPA protease, cleavage of ZPA at Asp156 is solely responsible for envelope hardening. Loss of envelope sperm binding was connected with conformational changes in ZP glycoproteins which masked or buried sperm ligand sites on ZP glycoproteins when the 
VE was converted to the FE. Therefore, ZPA proteolysis is a mechanism for envelope hardening and for blocking polyspermy.

As mentioned previously, the FE has an outer $F$ layer which is a heterocomplex of a cortical granule lectin and its jelly coat ligand. The glycoprotein ligand is located in the inner aspect of jelly coat layer $\mathrm{J}_{1}$ proximal to the egg envelope. The cortical granule lectin, which is the major macromolecular constituent of the cortical granules, is released into the perivitelline space, diffuses through the VE, binds to its ligand on the surface of the VE and forms an insoluble heteropolymer, the F layer (Nishihara et al., 1986). The $\mathrm{F}$ layer is bound to the outer surface of the envelope by an undetermined mechanism (Hedrick and Nishihara, 1991). The F layer prevents sperm from binding to the envelope surface. Although the mechanism is unknown, it seems likely that the $\mathrm{F}$ layer either physically blocks access to or competes for sperm binding sites on the of ZP glycoprotein glycans. In addition to blocking sperm access to the envelope, the $F$ layer effectively seals the space between the egg plasma membrane and the envelope (Nishihara and Hedrick, 1977). The F layer acts as a 'semipermeable membrane', permitting the passage of water and ions into the space, but preventing the escape of perivitelline space macromolecules. Accordingly, the osmotic pressure in the perivitelline space is increased and an influx of water occurs, increasing the volume of the space. As the envelope is flexible, it 'elevates' away from the egg surface. The cortical granule lectin is the 'molecular engine' that drives elevation of the egg envelope as it is the major soluble macromolecule in the perivitelline space (Nishihara et al., 1986). Thus, the long known elevation of the anuran egg envelope (which also occurs in many animal eggs) is mechanistically due to a cortical granule lectin binding to a jelly coat ligand, thereby forming a semi-permeable heterocomplex, the $\mathrm{F}$ layer (Morgan, 1897).

In summary, three molecular mechanisms for blocking polyspermy exist in anurans eggs. These mechanisms collectively prevent sperm binding to the egg envelope and hence, prevent sperm from reaching the egg surface. Cortical granule exocytosis releases a $\beta-\mathrm{N}$-acetylglucosaminidase enzyme which hydrolyzes terminal $\beta-\mathrm{N}$-acetyl glucosamine residues from glycan moieties of ZP glycoproteins, thereby preventing sperm binding. Proteases are also released in the cortical granule reaction. One protease hydrolyzes ZPA at a single residue in the N-terminal domain, thereby triggering a general conformation change of ZP glycoproteins. This conformational change masks or buries glycan moieties (ligands for sperm binding) which were not hydrolyzed by $\beta-\mathrm{N}$ acetylglucosaminidase. ZP glycoprotein conformation changes caused by ZPA hydrolysis also cause hardening of the egg envelope. Cortical granule exocytosis also releases a cortical granule lectin, which binds to its jelly coat ligand forming the F layer. The $\mathrm{F}$ layer prevents sperm from binding to the envelope surface. The F layer also functions as a semi-permeable heterocomplex, causing an influx of water into the perivitelline space resulting in FE elevation.

\section{Hatching}

The final biological process in which the anuran egg envelope functions is hatching of the embryo. It is knowledge of long standing that the anuran embryo hatching process involves physical and enzymatic mechanisms (Bles, 1905; Needham, 1963). In the case of $X$. laevis, hatching from the jelly coat layers appears to be primarily a physical phenomenon due to hydration of the jelly coat layers and an increase in the volume of the perivitelline space, likely controlled by the developing embryo (Carroll and Hedrick, 1974). Hatching from the FE is apparently caused by: 1) turgor pressure exerted on the FE by increases in the perivitelline space volume, 2) weakening of the FE due to limited proteolysis by a hatching enzyme released from epidermal cells in the frontal head region of the embryo (hatching gland cells), and 3) violent, thrashing movements of the tailed embryo which physically ruptures the filamentous envelope. These processes result in escape of the embryo from the region of the FE covering the head without frank dissolution or destruction of the entire FE. Extensive studies on the hatching process have also been reported for $B$. japonicus and $R$. chensinensis (for references, see (Katagiri, 1975; Yamasaki et al., 1990)).

The biosynthesis of hatching enzyme is a singular event in the life of an amphibian reaching a maximum at about Stage 31 in $X$. laevis (Katagiri et al., 1997), consistent with the classical morphological observations of hatching occurring at Stage 35/36 (Nieuwkoop and Faber, 1956). Biologically, small amounts of the enzyme are apparently needed since it is 'locally applied' by hatching glands cells to weaken the integrity of the FE thereby permitting escape of the embryo by physical forces (Carroll and Hedrick, 1974; Yoshizaki, 1991; Yoshizaki and Katagiri, 1975). The $X$. laevis enzyme was isolated and characterized as a $60 \mathrm{~K}$ MW protease, whose activity was inhibited by EDTA and $\mathrm{ZnCl}_{2}$ (Fan and Katagiri, 2001; Urch and Hedrick, 1981b). The enzyme selectively hydrolyzed the 112-120K glycoproteins of the FE, which includes ZPX and ZPY, but did not hydrolyze ZPB and ZPC, the major components of the FE (Urch and Hedrick, 1981a). The enzyme apparently does not hydrolyze components of the F layer (Yoshizaki, 1978; Yoshizaki and Yamasaki, 1991). It was proposed that the ZP glycoproteins hydrolyzed by hatching enzyme were key elements in maintaining the FE structure (Urch and Hedrick, 1981a). These elements (ZPX, ZPY?) bind together the ZP glycoprotein filaments (composed predominantly of ZPB and ZPC?), and are responsible for the 'structural integrity' of the FE architecture. By analogy, dismantling of a bridge is most easily done by 'removing' the nuts and bolts which 'bind together' the major structural elements such as the girders, cables, or braces. However, an exact understanding how the component ZP glycoproteins form supramolecular filamentous structures and how these filaments are integrated and organized to form the architecture of the envelope remains to be determined.

A cDNA clone for a gene selectively expressed in the dorsoanterior region of $X$. laevis embryos that coded for the hatching enzyme was fortuitously discovered (Katagiri et al., 1997). When the cDNA was expressed and antibodies prepared, the expressed protein was specifically localized to the hatching gland cells. The antibodies also inhibited the digestion of the FE by media containing the hatching enzyme. Additional experiments established that the cDNA clone corresponded to the hatching enzyme. The translated sequence predicted an astacinlike metalloprotease containing CUB domains (Fig. 2). These protein and enzymatic properties of the hatching enzyme predicted from the cDNA translation were consistent with those reported earlier using purified preparations of the enzyme (Urch and Hedrick, 1981b).

Thus, escape of the embryo from the FE is a simple process in 
terms of biochemical mechanisms. Apparently, a single astacinlike protease selectively hydrolyzes one or a few, compositionally-minor ZP glycoproteins which are critically important for maintaining the FE structure. This limited and selective hydrolysis compromises the physical integrity of the envelope whereby the embryo escapes by physically rupturing the otherwise intact FE.

\section{The domain structure of proteases acting on anuran ZP glycoproteins}

As described previously, several protease domains which hydrolyze ZP glycoproteins, or are associated with the egg extracellular matrix, have been cloned (Fig. 2). These include two Ser active-site protease domains associated with oviductin, three Ser active-site protease domains associated with ovochymase, and a single metallo active-site protease domain associated with the hatching enzyme. The domain structures of these proteases have some commonly shared features. Consistent with being secreted proteases, they possess signal peptides. Some have been identified as glycoproteins and all possess consensus sites for N-linked glycosylation. Enzymes, whose activities have been characterized, exist in proenzyme forms that are converted to active enzyme via limited proteolysis. All protease domains are associated with CUB domains. The mature or processed forms of oviductin, ovochymase, and the hatching enzyme all possess CUB domains. Due to these common domain features, CUB domains may have functional roles in assisting egg associated protease domains in cleaving peptide bonds on ZP glycoproteins or glycoproteins associated with egg ECM. Perhaps CUB domains bind to non-substrate sites, such as glycans, on ZP glycoproteins. Preliminary molecular modeling and docking computations suggested that an oviductin CUB domain has a glycan binding site (R. Almaraz et al., unpublished observations). CUB domains (8,635 domains in 3283 proteins) are found almost exclusively in animals, are commonly found in association with other protein domains and frequently with protease domains (Smart, 2007). However, in spite of the widespread distribution of CUBs, almost no experimental evidence exists establishing their biological roles as a common protein module. The concept that CUB domains may assist soluble enzymes in catalyzing the hydrolysis of insoluble substrates via a binding site separate from the catalytic site is currently under investigation.

\section{The ZP glycoprotein composition of pig oocytes}

\section{Isolation and biochemical composition}

Reports of the first isolation and composition of egg envelopes from pig and mouse oocytes were published simultaneously (Bleil and Wassarman, 1978; 1980; Dunbar et al., 1978; 1980). In contrast to isolation of envelopes from oviposited anuran eggs, it was technically simpler and more efficient in mammals to obtain oocytes from ovarian follicles than to induce ovulation and collect ovulated eggs from oviducts. However, envelopes can be recovered from ovulated mammalian eggs or embryos, although in much smaller numbers. In the mouse, oocytes were manually dissected from ovarian follicles using a microscope and a micropipette. Approximately 50 oocytes/hour were collected and the envelope physically separated from the cell. The protein content of an individual mouse envelope was $5 \mathrm{ngs}$ and therefore, about
250 ngs/hour of envelope protein could be isolated. In contrast, oocytes from pig ovaries were isolated en masse from slaughter house material. Approximately 40-50,000 oocytes were released from 200 ovaries using a ganged razor blade apparatus, the released oocytes harvested, gently homogenized, and envelopes isolated using sieving and centrifugation methods similar to those used for $X$. laevis envelope isolation. This process required 3-4 hours and yielded approximately $1.5 \mathrm{mgs}$ of envelope protein or $1.9 \mathrm{mgs}$ of glycoprotein (33 ngs of protein and $10 \mathrm{ngs}$ of glycans/ envelope). The isolated envelopes were estimated to be greater than $93 \%$ 'pure' as judged by chemical, enzymatic, and microscopic criteria. Thus, isolation of envelopes from the pig ovary was about 2,000 more efficient than from the mouse ovary. This greater efficiency was a reflection of the greater weight of an individual pig envelope relative to the mouse envelope, the ability to process larger numbers of ovaries and the higher yield of oocytes/ovary in the case of the pig.

However, the efficiency advantage of the pig system versus the mouse system for isolating large quantities of envelopes was neutralized by the extreme microheterogeneity of the pig ZP glycoproteins. This was due to the complexity of the glycan moieties of the ZP glycoproteins. The pig ZP glycoproteins could not be resolved by SDS-PAGE whereas the three mouse ZP glycoproteins, although exhibiting microheterogeneity, were separated by one dimensional electrophoresis. Pig ZP glycoproteins required 2D-PAGE methods for improved but yet incomplete separation. Additional immunological and chemical studies were required for identification of individual glycoproteins (Hedrick and Wardrip, 1987). Separation of individual glycoproteins required partial hydrolysis of glycoprotein glycans (Yurewicz et al., 1987). Identification and separation of the pig ZP glycoproteins was a major experimental challenge to several research groups (Brown and Cheng, 1986; Dunbar et al., 1991; Hasegawa et al., 1994; Menino and Wright, 1979; Yurewicz et al., 1987). It is now accepted that the pig oocyte envelope is composed of three glycoproteins, ZPA, ZPB, and ZPC. In 2D-PAGE, the three ZP glycoproteins yielded 'trains of spots' differing in molecular weights and isoelectric points. Some ZPB and ZPC charge and size isomers co-migrated and gave ' merging trains of spots'. ZPA gave one train of spots under non-reducing conditions and three trains of spots under reducing conditions. This was due to incomplete proteolysis of ZPA (90K) in the oocyte envelope, producing a glycopeptide $(25 \mathrm{~K})$ and a glycoprotein $(65 \mathrm{~K})$ products which were disulfide bond linked.

Comparison of the ZP glycoproteins present in oocyte, ovulated egg, and zygote envelopes was investigated using radiolabeling of the glycoproteins isolated from individual cells or zygotes using micropipettes and separated by 2D-PAGE (Hedrick et al., 1987). Envelopes from the follicular oocyte correspond to the $X$. laevis $\mathrm{OE}$, from the oviductal recovered ovulated egg to the VE, and from the zygote to the FE. Conclusions were: 1) The microheterogeneity of en masse isolated pig ZP glycoproteins was not due to population genetic variation, but rather to the intrinsic ZP glycoprotein biosynthetic pathways present in individual oocytes. 2) In addition to the ZP glycoproteins, the egg compared to the oocyte envelope had two additional macromolecules ( $82 \mathrm{~K}$ and $102 \mathrm{~K}$ ). Likely, these were contributed by the female reproductive tract. 3) The ZPA glycoprotein was completely hydrolyzed to $25 \mathrm{~K}$ and $65 \mathrm{~K}$ components in the zygote 
envelope probably by a protease(s) derived from the egg cortical granules. 4) Additional macromolecules found in the zygote envelope $(31 \mathrm{~K}, 35 \mathrm{~K}$, and $44 \mathrm{~K})$ were likely derived from cortical granules. Recently a cortical granule lectin previously identified in $X$. laevisegg cortical granules was shown to be present in pig egg cortical granules and released in the cortical reaction (Hedrick, 2007). The microheterogeneous glycoprotein had a MW of 40$45 \mathrm{~K}$ so it is likely that one or more of the additional macromolecules in the zygote envelope were the cortical granule lectin.

\section{cDNA cloning and protein domains}

cDNA cloning of the three pig ZP glycoproteins was first accomplished by Yurewicz et al. (Yurewicz et al., 1993a) and Harris et al. (Harris et al., 1994). The predicted protein domains of the ZP glycoproteins are illustrated in Fig. 1. The pig ZP glycoproteins contained domains conserved in all ZP glycoproteins including a signal sequence, sequons for $\mathrm{N}$-linked glycosylation, ZP domains, furin cleavage sites, and transmembrane sequences. Substantial proteolytic processing of ZP glycoprotein $\mathrm{N}$-terminal regions was also noted by these authors and they were the first to recognize that ZP glycoproteins were biosynthesized via the constituitive secretory pathway for glycoproteins.

\section{Biophysics and biochemistry of pig egg envelopes}

\section{Envelope forms have different ultrastructures}

Prior to ovulation, the pig oocyte envelope in situ has villar processes embedded in the matrix of the envelope contributed by the oocyte itself and the surrounding cumulus cells. The morphology is similar to that of anuan oocyte envelopes. These villar processes were largely pulled out or sheared off in the isolation process. The isolated pig OE, as determined by TEM, had an asymmetry or morphological 'sidedness' due to the spaces in the OE formerly occupied by villar processes (Dunbar et al., 1980). The fibrillar matrix of the in situ and isolated OE had the same general appearance.

Surface morphologies, as determined by SEM, of various forms of pig envelopes in situ were recently published (Michelmann et al., 2007). Substantial variation in surface morphology was observed between and within oocytes and embryos. In vivo versus in vitro differences between oocytes and embryos were also observed. However, four types of morphologies were described from net-like surfaces with prominent fibrils and pores (Type I) transitioning to smooth surfaces without prominent fibrils and pores (Type IV). Type I was more typical of immature oocytes (OE) whereas Type IV was more typical of embryos (FE). From their in vitro observations, the authors concluded it was clear that there were differences between pig oocytes, ovulated eggs, and early embryos, with a shift from porous and reticular to even and smooth surfaces. Similar morphological changes have been reported in human and cattle (Nikas et al., 1994; Suzuki et al., 1994). These observations of changes in the pig envelope surfaces are in keeping with those of $X$. laevis envelope surfaces where there is also a change from a porous reticular surface of the body cavity egg CE to an even, smooth surface of the embryo FE (Larabell and Chandler, 1989; 1990). It may be that these morphological changes in pig and $X$. laevis envelopes are a reflection of shared biochemical and biophysical modifications of envelope ZP glycoproteins (Flechon et al., 2004). These physicochemical modifications in pig envelopes are likely caused by female reproductive tract and/or egg associated macromolecules (enzymes and binding proteins/glycoproteins) acquired in the reproductive tract or released/activated in the cortical reaction, analogous with those in $X$. laevis.

\section{Solubilization of pig envelopes}

Solubilization of isolated pig OE under various conditions was determined (Dunbar et al., 1980). In general, solubility increased with an increase in $\mathrm{pH}$ and temperature and decreased with ionic strength. Disulfide bonds are intramolecular within ZP glycoproteins and intermolecular bonds are absent (Green, 1989; Kanai et al., 2007). Chaotropic agents such as SDS and urea effectively dissolved the pig OE. The rate of OE dissolution in buffered solutions was increased with temperature. The pig OE had $a \mathrm{~T}_{m}$ of $52^{\circ} \mathrm{C}$ compared with the $X$. laevis $\mathrm{CE}$ of $51^{\circ} \mathrm{C}$ (sodium borate buffers, $\mathrm{pH} 9-10$ ). Thus, the structural integrity of the pig OE envelope was maintained by noncovalent interactions of the ZP glycoproteins. These properties are similar to those of the $X$. laevis envelope and lead to similar conclusions, namely, that interaction of pig ZP glycoproteins to form hetero molecular aggregates, the formation and assembly of aggregates into higher order structures such as filaments, and the fine structure and overall architecture of the envelope are due to non-covalent interactions.

\section{Deformability measurements}

Biophysical measurements of pig envelopes equivalent to those carried out with $X$. laevis envelopes have not been performed. Measurements in other systems, however, show differences in the biophysical properties of egg envelopes before and after fertilization e.g., increased resistance to dissolution as a function of $\mathrm{pH}$, temperature, sodium periodate oxidation, and protease hydrolysis (for reviews see Green, 2002; Wolf, 1981). Measurements of in situ envelope deformability were made in hamster and mouse eggs and embryos (Drobnis et al., 1988). In both cases, the FE form of the envelope was more stiff or less flexible i.e., less deformable by a unit measure of force. In the hamster envelope deformability decreased by 2.3 fold versus 1.5 fold in the mouse versus 17 fold in $X$. laevis.

\section{Chemical changes in the pig ZP glycoproteins}

As mentioned previously, the pig ZPA glycoprotein (90K) can be $\mathrm{N}$-terminally processed to an $\mathrm{N}$-terminal domain containing a $25 \mathrm{~K}$ glycopeptide and a C-terminal domain containing $65 \mathrm{~K}$ glycoprotein connected by disulfide bonds. The sequence site of hydrolysis is D168-E169. N-terminal processing occurs to some extent while the oocyte is in the ovarian follicle. Upon fertilization, proteolysis goes to completion and the $90 \mathrm{~K}$ form of the ZPA glycoprotein is missing from the pig FE (Hedrick et al., 1987). ZPA proteolysis also occurs in human and cattle envelopes at fertilization (Harris et al., 1994). An N-terminal domain consensus sequence site $(X+D-D / D-E)$ for proteolytic processing of ZPA was identified in three anuran and six mammalian ZPA sequences (including $X$. laevis and pig) (Lindsay and Hedrick, 2004). As mentioned earlier, an egg associated 
metalloprotease with BMP-1-like properties was identified in $X$. laevis. It seems likely that this fertilization-associated envelope processing event is mechanistically conserved, and egg associated ZPA proteases will be found in other species, including the pig.

Other chemical changes in pig ZP glycoproteins have been inferred but not chemically defined. A significant acid shift in the isoelectric points of ZPA, ZPB, and ZPC was observed with in vitro oocyte maturation (analogous to the $X$. laevis CE to VE conversion?) (Rath et al., 2005). Modification of the glycan moieties of the ZP glycoproteins was proposed, either by sialylation or sulfation. However, differences in glycan structures in the ZP glycoproteins between the immature and mature oocyte have yet to be demonstrated.

\section{Pig ZP glycoprotein glycans}

\section{Glycan structures}

Several structural studies on the $\mathrm{N}$ - and O-linked glycan moieties of the isolated pig ZP glycoproteins have been published. Separation and isolation of pig ZPB and ZPC glycoproteins using HPLC methods required treatment of the glycoproteins with endo- $\beta$-galactosidase which partially hydrolyzed the $\mathrm{N}$-acetyllactosamine repeating units in $\mathrm{N}$ - or $\mathrm{O}$-linked glycans. This necessary procedure compromised the complete determination of $\mathrm{N}$ - and $\mathrm{O}$-glycans in pig ZP glycoproteins. However, a sufficient understanding of glycan structures has been obtained and related to the sperm binding functions of pig ZP glycoproteins.

Linear O-linked glycans were present in ZPB and ZPC but absent in ZPA. All three ZP glycoproteins contain branched $\mathrm{N}$ linked glycans. Structural studies on the neutral N-linked glycans elucidated more than 30 structures of the complex type (Mori et al., 1991). No high Man or hybrid types of glycans were detected. Bi-antennary, 2,4-branched and 2,6-branched triantennary, and tetra-antennary glycans with fucosylated trimannosyl cores were identified in the molar ratio of $4: 2: 1: 1$. A significant fraction of these (26\%) contained up to three linear $\mathrm{N}$-acetyllactosamine repeating units. Approximately $39 \%$ of the glycans contained a terminal $\beta-\mathrm{N}$-acetylglucosamine residue with the remainder being terminal $\beta$-galactose residues.

The acidic $\mathrm{N}$-linked glycans were also characterized as bi-, tri- and tetra-antennary structures with $\mathrm{N}$-acetyllactosamine repeating units (Mori et al., 1998). They were characterized as being sialylated without sulfate or sulfated $\mathrm{N}$-acetyllactosamine repeats of different lengths and differing in the number of monosulfated $\mathrm{N}$-acetyllactosamine units.

The linear O-linked glycans of pig ZPB and ZPC glycoproteins were also a heterogeneous mixture of structures, both neutral and acidic. The neutral O-glycans had type-1 (70\%) and type-3 (6\%) core structures (Hirano et al., 1993; Hokke et al., 1994; Von Witzendorff et al., 2005). Those with type-1 core structures terminated in either $\beta$-galactosyl residues $(54 \%)$ or $\beta$-N-acetylglucosamine residues (16\%). The acidic O-glycans were principally composed of a series of sialylated and sulfated glycans with linear $\mathrm{N}$-acetyllactosamine repeating units. Sulfation was predominantly on internal $\mathrm{N}$-acetylglucosamine residues. The sialic acid was either Neu5Gc or Neu5Ac in a 2:1 ratio. Longer chains were terminated with sialyl residues whereas shorter chains were terminated with $\beta$-galactose or $\beta-\mathrm{N}$ acetylglucosamine residues. Minor amounts of other structures were also present.

\section{Protein sites of glycosylation}

Pig ZPC has 5 potential N-glycosylation sites, N124, 146, 179, 225, and 271 (Yonezawa et al., 1999). Complex N-linked glycans were attached to N124, 146, and 271. All three sites had biantennary glycans while tri- and tetra-antennary glycans were located primarily at N271. The glycan structures characterized were largely neutral glycans as separation of ZPB and ZPC glycoproteins by HPLC methods required digestion with endo- $\beta$ galactosidase to reduce the microheterogeneity of the glycoproteins. Endo- $\beta$-galactosidase incompletely hydrolyzed the acidic complex ZP glycans. Sialylated glycans and some with sulfation were resistant to enzymatic hydrolysis. Accordingly, approximately $1 / 3-1 / 2$ of the glycans at N124, 146, and 271 were acidic glycans of heterogeneous lengths which were not further characterized. Pig ZPC contained O-linked glycans located at T161 and 162 (Fig. 1).

Pig ZPB has 5 potential N-glycosylation sites, N70, 203, 220, 33, and 474 (Kudo et al., 1998). N474 is C-terminal to the furin cleavage site and is not present in the mature glycoprotein. Complex N-linked glycans were attached to N203, 220, and 333. As with ZPC, all three sites had biantennary glycans while tri- and tetra-antennary glycans were localized primarily at N220. As with ZPC, separation of ZP glycoproteins was only possible after endo- $\beta$-galactosidase treatment so structure determination of acidic glycans was not accomplished. However, acidic glycans predominated at the $\mathrm{N} 203$ and 220 glycosylation sites, whereas neutral glycans predominated at the N333 site. Pig ZPB contained O-linked glycans located at two sites, S293, T303 (Fig. 1).

Pig ZPA has 6 potential N-glycosylation sites, N84, 93, 268, 316,323 , and 530. N-linked glycans were attached to five of these sites, N84 or 93, 268, 316, 323, and 530 (Von Witzendorff et al., 2005). Most glycans were neutral biantennary having galactose and glucosamine residues with lesser amounts of tri- and tetraantennary glycans. Minor amounts of glycans had $\mathrm{N}$ acetyllactosamine repeat structures with terminal sialylation. In contrast to reports of others that pig ZP glycoproteins did not contain high mannose glycans, a Man5 glycan was found, likely associated with N268 (Fig. 1). The 2D-PAGE electrophoretic properties of ZPA were relatively insensitive to endo- $\beta$-galactosidase treatment, in contrast to ZPB and ZPC, due to the low abundance of acidic $\mathrm{N}$-acetyllactosamine repeat structures.

\section{Sperm binding to pig ZP glycoproteins}

Sperm binding to pig ZP glycoproteins requires the carbohydrate moiety as deglycosylated ZP proteins are not ligands for sperm binding (Berger et al., 1989; Sacco et al., 1989). Initial studies on sperm binding using pig ZP glycoproteins suggested that ZPB was the glycoprotein with ligand activity and ZPC had no ligand activity (Sacco et al., 1989). However, subsequent studies found a mixture of ZPB and ZPC glycoproteins acted synergistically in sperm binding assays (Yurewicz et al., 1998). The original observation that ZPB was the ligand for sperm binding was due to contamination of isolated ZPB with ZPC, and the formation of heterocomplexes. It was observed that in the pig system, a mixture of isolated ZPB and ZPC glycoproteins formed 
heteropolymers with MWs of $10^{6}$ or greater. The ZPB-ZPC complexes were the functional ligand units for sperm binding, as will be discussed below. The MW of the pig ZPB-ZPC heteropolymers is reminiscent of the high MW ZP glycoprotein aggregates generated from the heat solubilized $X$. laevis envelopes (discussed previously). Sperm binding experiments in $X$. laevis also suggested that heteropolymers of ZP glycoproteins were the functional ligand units for sperm binding (Vo and Hedrick, 2000). In the pig egg OE, 70\% of the total ZP glycoprotein is ZPB + ZPC in a 1:1 stoichiometry (Hedrick and Wardrip, 1986). In the $X$. laevis VE, $69 \%$ of the total ZP glycoprotein is ZPB + ZPC in a 1:1 stoichiometry (Hedrick and Hardy, 1991). A similar composition and stoichiometry exists in the VE of $B$. arenarum (Barisone et al., 2007). Thus, in $B$. arenarum, $X$. laevis and the pig, ZPB-ZPC complexes are likely the structures that provide high affinity ligands for sperm/envelope binding. Formation of a similar ZPB-ZPC complex in the chicken envelope was recently proposed (Okumura et al., 2007; Sasanami et al., 2006).

Analysis of sperm binding in the pig used envelopes in situ on oocytes or solid phase binding assays using sperm membranes. ZP glycoproteins were added to compete with sperm binding to the envelope or to solid phase surfaces using labeled ZP glycoproteins. Isolated ZPA, ZPB, or ZPC did not compete with sperm binding, whereas ZPB/ZPC mixtures did compete (Yonezawa et al., 1995b). ZPA did not compete with labeled ZPB/ZPC complexes in binding to sperm membranes (Yurewicz et al., 1993b). Therefore, ZPA does not contribute to sperm binding in the pig. Elimination of O-linked glycans from ZPB was without effect on inhibition of sperm binding, whereas elimination of $\mathrm{N}$-linked chains markedly reduced the inhibitory effect (Yonezawa et al., 1995a). Of the $\mathrm{N}$-linked chains, the neutral tri- and tetra-antennary complex glycans of ZPB are the most potent ligands (Kudo etal., 1998; Yonezawa et al., 2005). Removal of the terminal galactose residues from ZPB-ZPC complexes, or from isolated neutral Nlinked glycans significantly reduced inhibitory activity (Yonezawa et al., 2005). Isolated O- and N-linked glycans inhibited sperm binding, with $\mathrm{N}$-linked glycan inhibition more potent than O-linked glycan inhibition (Noguchi et al., 1992; Yurewicz et al., 1991). However, glycans inhibition was 2-3 orders of magnitude lower than ZP glycoprotein inhibition. This observation was interpreted that the polypeptide chain was necessary for high affinity interactions of glycans with sperm due to localization and/or orientation effects. In summary, the current model of a ZP glycoprotein ligand for sperm binding in the pig is the following. A ZPB-ZPC glycoprotein complex is structurally required for generation of high affinity ligands for sperm binding. The neutral $\mathrm{N}$-linked tri- and tetraantennary glycans with terminal $\beta$-galactose residues function as the ligand sites for sperm binding. These glycans must also be appropriately located and oriented on the ZPB, and possibly the ZPC, protein moieties.

This model of sperm binding to ZPB-ZPC complexes is supported by substantial experimental results. However, complete determination of glycan structures of pig ZP glycoproteins and an understanding of how the glycans and polypeptide backbones of ZPB and ZPC interact synergistically to form structural and functional complexes is needed for a robust model. Observations inconsistent with this model also exist e.g., treatment of oocytes with $\beta$-N-acetylglucosaminidase eliminated sperm binding to the envelope (Berger et al., 1989). Methods of quantifying sperm binding in mammals are problematic. For instance, using competitive sperm binding methods, only low values of inhibition are observed with ZP glycoproteins, and often $50 \%$ or less is the maximum observed in competitive binding assays (Yonezawa et al., 2005; Yonezawa et al., 1995a). These observations suggest alternative mechanisms to those described above involving specific glycan structures exist for sperm binding to the egg envelope. Thus, additional structural and functional studies are required to validate the model proposed above. Direct binding methods, rather than competitive ones, are also needed for quantifying the rate and strength of sperm binding to the ZP and ZP glycoprotein structures, thereby providing more convincing and indisputable connections between glycoprotein structures and sperm binding functions.

\section{Blocks to polyspermy in pig eggs}

Prevention of polyspermy is a biologically important fertilization process in all animals as polyspermy causes aberrant development and embryo death. However, it is of particular interest in the pig (Wang et al., 2003). Polyspermy rates for in vivo fertilization (30-40\%) are higher than for other animals. Rates for in vitro fertilization often exceed $50 \%$. Polyspermy is "the major obstacle to successful production of large numbers of in vitro produced pig embryos with high levels of developmental competence. " (Day, 2000)

An envelope block to polyspermy in mammalian eggs was first observed by Austin and Braden (Austin and Braden, 1956). They suggested that the envelope block to sperm penetration was associated with the loss of cortical granules (cortical or zona reaction) induced by the fertilizing sperm. Barros and Yanagimachi demonstrated that the envelope block was due to factors associated with the cortical granules (Barros and Yanagimachi, 1971). Gwatkin and Williams showed that the cortical granule factors were heat labile, inhibited by soybean trypsin inhibitor, and apparently not species specific i.e., factors from the hamster egg were effective on the mouse egg (Gwatkin and Williams, 1974). They proposed a cortical granule trypsin-like protease biochemically modified the egg envelope and prevented sperm binding. Binding of soybean trypsin inhibitor to substances in hamster cortical granules was observed, validating the concept of a cortical granule protease (Cherr et al., 1988). Protease activity in a partially purified fraction from mouse eggs not sensitive to soy bean trypsin inhibitor was reported (Moller and Wassarman, 1989). However, it likely is a different proteolytic activity than those previously described. Unfortunately, no subsequent biochemical studies of mammalian cortical granule proteases have been published.

As previously mentioned, in $X$. laevis, three proteolytic activities were associated with the egg and/or the cortical granules chymotrypsin-like, trypsin-like, and metalloprotease activities. The metalloprotease activity caused the cleavage of ZPA thereby inducing conformation changes in the ZP glycoproteins resulting in envelope hardening. In $X$. laevis, envelope hardening is associated with a block to polyspermy reaction. Conformational changes in ZP glycoproteins that harden the envelope also result in the loss of sperm binding sites. Since the pig ZPA also undergoes proteolytic N-terminal processing connected with the cortical reaction perhaps the cortical granule enzyme(s) responsible for hardening of the pig egg envelope is a metalloprotease. Similar 
proteases and proteolytic mechanisms may be used in the pig and $X$. laevis to alter the conformation of ZP glycoproteins, thereby hardening the envelope and modifying ligand sites for sperm binding.

The hydrolytic activity of a glycosidase on ZP ligand sites important for sperm binding is a possible biochemical mechanism for blocking polyspermy in pig eggs. Treatment of oocytes with $\beta$-N-acetylglucosaminidase eliminated the activity of the ZP for sperm binding (Berger et al., 1989). As was mentioned previously, a $\beta$-N-acetylglucosaminidase activity associated with the cortical granules of $X$. laevis eggs is released in the cortical reaction. This glycosidase hydrolyzed $\beta-\mathrm{N}$ acetylglucosamine residues from ZPC glycans which functioned as ligands for sperm binding. $\beta-\mathrm{N}$-acetylglucosaminidase is known to be present in the cortical granules of mouse eggs and released in the cortical reaction (Miller et al., 1993). However, observations of such an enzyme in pig cortical granules and hydrolysis of $\beta-\mathrm{N}$-acetylglucosamine residues from pig ZPB/ZPC glycans have not been reported.

A major secretory product of the mammalian oviduct is a high MW oviduct specific glycoprotein termed OGP. In the pig, OGP binds to the zona pellucida, the perivitelline space, and the plasma membrane of the egg (Mccauley et al., 2003). Addition of OGP to eggs reduced the incidence of polyspermy i.e., it provides a block to polyspermy. A suggested mechanism for blocking polyspermy was OGP binding to the envelope surface thereby forming of a barrier to sperm binding or occupying/ modifying ligand sites on the ZP glycoproteins for sperm binding. This OGP binding proposal would reduce the number of sperm binding to or penetrating the egg envelope, thereby reducing the number of sperm fusing with the egg.

An lectin-ligand binding mechanism was recently described as a possible polyspermy block (Hedrick, 2007). This mechanism proposed the release of a cortical granule lectin which binds to the glycans of the ZP glycoproteins, thereby occupying binding sites on the ZP glycoproteins or otherwise forming a barrier to sperm binding. This mechanism is similar to the lectinligand binding reaction that blocks sperm-envelope binding and produces the lectin-ligand heterocomplex forming the $\mathrm{F}$ layer of the $X$. laevis FE.

It was recently suggested that sperm and oviduct ubiquitin Cterminal hydrolases may be involved in blocking polyspermy in the pig (Yi et al., 2007). Ubiquitin C-terminal hydrolase activity exists in oviductal fluid and ubiquitination of ZP glycoproteins was observed. Proteasomes bind to and hydrolyze ubiquitinated proteins. Proteasomes are associated with pig sperm (Sutovsky et al., 2004). Preliminary proteomic analysis of pig ZP glycoproteins identified ZPC as a ubiquitinated glycoprotein. It was proposed that alteration of ZPC glycoproteins by a ubiquitinationproteasome mechanism could reduce the sperm binding properties of the envelope thereby establishing a block to polyspermy.

Thus, there are several possible envelope modifying mechanisms for blocking polyspermy in pig eggs. Additional experiments are needed to identify which of these possible mechanisms are actually used by the pig egg to protect itself against polyspermy. In comparison with anuran egg mechanisms, it is likely that more than one mechanism for blocking polyspermy exists in the pig. How these polyspermy blocking mechanisms are coordinated in the egg, and why they apparently fail with greater frequency in the pig than in other animals will be of considerable interest to gamete biologists in the future.

\section{Dedication}

This paper is dedicated to the late David Garbers in remembrance of good friendship, warm scientific collegiality, and happy times at Gordon Research Conferences. It is also dedicated to the late Mary Ann Kutryk Bakos (1957-2007), colleague and graduate student, who made seminal observations on the biochemistry and biophysics of $\mathrm{X}$. laevis egg envelopes.

\section{References}

ANDERSON, E. (1974). Comparative aspects of the ultrastructure of the female gamete. International Review of Cytology 4: 1-70.

AUSTIN, C.R. and BRADEN, A.W.H. (1956). Early reactions of the rodent egg to spermatozoon penetration. Journal of Experimental Biology 33: 358-365.

AUSTIN, C.R. (1968). Ultrastructure of Fertilization. Holt, Rinehart, and Winston, New York.

BAKOS, M.A., KUROSKY, A. and HEDRICK, J.L. (1990a). Physicochemical characterization of progressive changes in the xenopus-laevis egg envelope following oviductal transport and fertilization. Biochemistry 29: 609-615.

BAKOS, M.A., KUROSKY, A. and HEDRICK, J.L. (1990b). Enzymatic and envelope-converting activities of pars recta oviductal fluid from xenopus-laevis. Developmental Biology 138: 169-176.

BARISONE, G.A., HEDRICK, J.L. and CABADA, M.O. (2002). Vitelline envelope of Bufo arenarum: Biochemical and biological characterization. Biology of Reproduction 66: 1203-1209.

BARISONE, G.A., KRAPF, D., CORREA-FIZ, F., ARRANZ, S.E. and CABADA, M.O. (2007). Glycoproteins of the vitelline envelope of amphibian oocyte: Biological and molecular characterization of ZPC component (gp41) in Bufo arenarum. Molecular Reproduction and Development 74: 629-640.

BARROS, C. and YANAGIMACHI, R. (1971). Induction of zona reaction in golden hamster eggs by cortical granule material. Nature 233: 268-269.

BERGER, T., DAVIS, A., WARDRIP, N.J. and HEDRICK, J.L. (1989). Sperm binding to the pig zona pellucida and inhibition of binding by solubilized components of the zona pellucida. Journal of Reproduction and Fertility 86: 559565.

BLEIL, J.D. and WASSARMAN, P.M. (1978). Identification and characterization of proteins of zona pellucida. Journal of Cell Biology 79: A173-A173.

BLEIL, J.D. and WASSARMAN, P.M. (1980). Structure and function of the zona pellucida - identification and characterization of the proteins of the mouse oocytes zona pellucida. Developmental Biology 76: 185-202.

BLES, E.J. (1905). The life history of Xenopus laevis (daud.). Transaction of the Royal Society, Edinburgh 41: 789-821.

BROWN, C.R. and CHENG, W.T.R. (1986). Changes in the composition of the porcine zona pellucida during development of the oocyte to the 2- to 4-cell embryo. Journal of Embryology and Experimental Morphology 92: 183-191.

CAL, S., MONCADA-PAZOS, A. and LOPEZ-OTIN, C. (2007). Expanding the complexity of the human degradome: Polyserases and their tandem serine protease domains. Frontiers in Bioscience 12: 4661-4669.

CALLEBAUT, I., MORNON, J.P. and MONGET, P. (2007). Isolated ZP-N domains constitute the $\mathrm{N}$-terminal extensions of zona pellucida proteins. Bioinformatics 23: 1871-1874.

CAMPANELLA, C., AMORE, F., PITARI, G., FUSCO, C., MAURIZI, G. and DUPRE, S. (1992). Postfertilization changes in Discoglossus-pictus (anura) eggs result in the formation of a capsular chamber where the egg rotates. International Journal of Developmental Biology 36: 413-422.

CAMPANELLA, C., CAROTENUTO, R., INFANTE, V., MATURI, G. and ATRIPALDI, U. (1997). Sperm-egg interaction in the painted frog (Discoglossus pictus): An ultrastructural study. Molecular Reproduction and Development 47: 323-333.

CAPUTO, M., INFANTE, V., TALEVI, R., VACCARO, M.C., CAROTENUTO, R. and CAMPANELLA, C. (2001). Following passage through the oviduct, the coelomic envelope of Discoglossus pictus (amphibia) acquires fertilizability upon reorga- 
nization, conversion of gp 42 to gp 40 , extensive glycosylation, and formation of a specific layer. Molecular Reproduction and Development 58: 318-329.

CAPUTO, M., RicCiO, S., PAGlieRUCCI, P., TRETOlA, L., DIGLIO, C., CAROTENUTO, R., DE MARCO, N. and CAMPANELLA, C. (2005). Sulphated glycoconjugates are powerful inhibitors of spermatozoa binding to the vitelline envelope in amphibian eggs. Biology of the Cel/97: 435-444.

CARROLL, E.J. and HEDRICK, J.L. (1974). Hatching in toad xenopus-laevis morphological events and evidence for a hatching enzyme. Developmental Biology 38: 1-13.

CHERR, G.N., DROBNIS, E.Z. and KATZ, D.F. (1988). Localization of cortical granule constituents befor and after exocytosis in the hamster egg. Journal of Experimental Zoology 246: 81-93.

CONNER, S.J., LEFIEVRE, L., HUGHES, D.C. and BARRATT, C.L.R. (2005) Cracking the egg: Increased complexity in the zona pellucida. Human Reproduction 20: 1148-1152.

DAY, B.N. (2000). Reproductive biotechnologies: Current status in porcine reproduction. Animal Reproduction Science 60: 161-172.

DROBNIS, E.Z., ANDREW, J.B. and KATZ, D.F. (1988). Biophysical properties of the zona pellucida measured by capillary suction. Is zona hardening a mechanical phenomenon? Journal of Experimental Zoology 245: 206-219.

DUMONT, J.N. (1972). Oogenesis in Xenopus laevis. Part 1. Stages of oocyte development in laboratory maintained animals. Journal of Morphology 136: 153-180.

DUMONT, J.N. and BRUMMETT, A.N. (1985). Egg envelopes in vertebrates. In: BROWDER, L.W., Ed. Oogenesis. Plenum Press, New York, pp. 235-288.

DUNBAR, B.S., WARDRIP, N.J. and HEDRICK, J.L. (1978). Isolation and physicochemical properties of porcine zona pellucida. Journal of Cell Biology79: A163A163.

DUNBAR, B.S., WARDRIP, N.J. and HEDRICK, J.L. (1980). Isolation, physicochemical properties, and macromolecular-composition of zona pellucida from porcine oocytes. Biochemistry 19: 356-365.

DUNBAR, B.S., PRASAD, M. and TIMMONS, T.M. (1991). Comparative structure and funciton of mammalian zonae pellucidae. In: DUNBAR, B.S. and O'RAND, M.G., Eds., A Comparative Overview of Mammalian Fertilization. Plenum Press, New York.

FAN, T.J. and KATAGIRI, C. (2001). Properties of the hatching enzyme from Xenopus laevis. European Journal of Biochemistry 268: 4892-4898.

FLECHON, J.E., KOPECNY, V., PIVKO, J., PAVLOK, A. and MOTLIK, J. (2004). Texture of the zona pellucida of the mature pig oocyte. The mammalian egg envelope revisited. Reproduction Nutrition Development 44: 207-218.

GERTON, G.L., WARDRIP, N.J. and HEDRICK, J.L. (1982). A gel eluter for recovery of proteins separated by polyacrylamide-gel electrophoresis. Analytical Biochemistry 126: 116-121.

GERTON, G.L. and HEDRICK, J.L. (1986a). The celomic envelope to vitelline envelope conversion in eggs of xenopus-laevis. Journal of Cellular Biochemistry 30: 341-350.

GERTON, G.L. and HEDRICK, J.L. (1986b). The vitelline envelope to fertilization envelope conversion in eggs of xenopus-laevis. Developmental Biology 116: 17.

GREEN, D.P.L. (1989). Effect of sodium dodecyl-sulfate on the hamster zona pellucida before and after a cortical reaction induced by the ionophore a23187. Journal of Reproduction and Fertility 87: 447-453.

GREEN, D.P.L. (2002). Fertilization biophysics. In: HARDY, D.M., Ed. Fertilization. Academic Press, San Diego, pp. 387-399.

GREVE, L.C., PRODY, G.A. and HEDRICK, J.L. (1985). N-acetyl- $\beta$-Dglucosaminidase activity in the cortical granules of xenopus-laevis eggs. Gamete Research 12: 305-312.

GREY, R.D., WOLF, D.P. and HEDRICK, J.L. (1972). Formation of fertilization envelope in eggs of xenopus-laevis. Journal of Cell Biology 55: A96-A96.

GREY, R.D., WORKING, P.K. and HEDRICK, J.L. (1976). Evidence that fertilization envelope blocks sperm entry in eggs of xenopus-laevis - interaction of sperm with isolated envelopes. Developmental Biology 54: 52-60.

GREY, R.D., WORKING, P.K. and HEDRICK, J.L. (1977). Alteration of structure and penetrability of vitelline envelope after passage of eggs from coelom to oviduct in xenopus-laevis. Journal of Experimental Zoology 201: 73-\&.
GWATKIN, R.B.L. and WILLIAMS, D.T. (1974). Heat sensitivity of cortical granule protease from hamster eggs. Journal of Reproduction and Fertility 39: 153-155.

HARDY, D.M. and HEDRICK, J.L. (1992). Oviductin - purification and properties of the oviductal protease that processes the molecular-weight 43000 glycoprotein of the xenopus-laevis egg envelope. Biochemistry 31: 4466-4472.

HARRIS, J.D., HIBLER, D.W., FONTENOT, G.K., HSU, K.T., YUREWICZ, E.C. and SACCO, A.G. (1994). Cloning and characterization of zona-pellucida genes and cDNAs from a variety of mammalian-species - the ZPA, ZPB and ZPC gene families. DNA Sequence 4: 361-393.

HASEGAWA, A., KOYAMA, K., OKAZAKI, Y., SUGIMOTO, M. and ISOJIMA, S. (1994). Amino acid sequence of a porcine zona pellucida glycoprotein ZP4 determined by peptide mapping and cDNA cloning. Journal of Reproduction and Fertility 100: 245-255.

HEDRICK, J.L. and WARDRIP, N.J. (1986). Isolation of the zona-pellucida and purification of its glycoprotein families from pig oocytes. Analytical Biochemistry 157: $63-70$.

HEDRICK, J.L. and WARDRIP, N.J. (1987). On the macromolecular-composition of the zona-pellucida from porcine oocytes. Developmental Biology 121: 478488.

HEDRICK, J.L., WARDRIP, N.J. and BERGER, T. (1987). Differences in the macromolecular-composition of the zona-pellucida isolated from pig oocytes, eggs, and zygotes. Journal of Experimental Zoology 241: 257-262.

HEDRICK, J.L. and HARDY, D.M. (1991). Isolation of extracellular-matrix structures from xenopus-laevis oocytes, eggs, and embryos. Methods in Cel/ Biology 36: $231-247$.

HEDRICK, J.L. and NISHIHARA, T. (1991). Structure and function of the extracellular-matrix of anuran eggs. Journal of Electron Microscopy Technique 17: 319335.

HEDRICK, J.L. (1996). Comparative structural and antigenic properties of zona pellucida glycoproteins. Journal of Reproduction and Fertility. 9-17.

HEDRICK, J.L. (2007). A comparative analysis of molecular mechanisms for blocking polyspermy: Identification of a lectin-ligand binding reaction in mammalian eggs. In: GUPTA, S.K., KOYAMA, K. and MURRAY, J.F., Eds., Gamete Biology: Emerging Frontiers in Fertility and Contraceptive Development. Nottingham Press, Nottingham, pp. 409-420.

HIRANO, T., TAKASAKI, S., HEDRICK, J.L., WARDRIP, N.J., AMANO, J. and KOBATA, A. (1993). O-linked neutral sugar chains of porcine zona pellucida glycoproteins. European Journal of Biochemistry 214: 763-769.

HIYOSHI, M., TAKAMUNE, K., MITA, K., KUBO, H., SUGIMOTO, Y. and KATAGIRI, C. (2002). Oviductin, the oviductal protease that mediates gamete interaction by affecting the vitelline coat in Bufo japonicus: Its molecular cloning and analyses of expression and posttranslational activation. Developmental Biology 243: 176-184.

HOKKE, C.H., DAMM, J.B.L., PENNINKHOF, B., AITKEN, R.J., KAMERLING, J.P. and VLIEGENTHART, J.F.G. (1994). Structure of the o-linked carbohydrate chains of porcine zona pellucida glycoproteins. European Journal of Biochemistry 221: 491-512.

HUGHES, D.C. (2007). ZP genes in avian species illustrate the dynamic evolution of the vertebrate egg envelope. Cytogenetic and Genome Research 117:86-91.

IWAO, Y. and KATAGIRI, C. (1982). Properties of the vitelline coat lysin from toad sperm. Journal of Experimental Zoology 219: 87-95.

IWAO, Y. (2000a). Mechanisms of egg activation and polyspermy block in amphibians and comparative aspects with fertilization in other vertebrates. Zoological Science 17: 699-709.

IWAO, Y. (2000b). Fertilization in amphibians. In: TARIN, J.J. and CANO, A., Eds., Fertilization in Protozoa and Metazoan Animals. Springer-Verlag, Heidelberg, pp. 147-191.

JOVINE, L., QI, H.Y., WILLIAMS, Z., LITSCHER, E. and WASSARMAN, P.M. (2002). The ZP domain is a conserved module for polymerization of extracellular proteins. Nature Cell Biology 4: 457-461.

JOVINE, L., DARIE, C.C., LITSCHER, E.S. and WASSARMAN, P.M. (2005). Zona pellucida domain proteins. Annual Review of Biochemistry 74: 83-114.

KANAI, S., KITAYAMA, T., YONEZAWA, K., SAWANO, Y., TANOKURA, M. and NAKANO, M. (2007). Disulfide linkage patterns of pig zona pellucida glycoprotein ZP3 and ZP4. Molecular Reproduction and Development In Press On-line: DOI 10.1002/mrd.20836. 
KANAMORI, A. (2000). Systematic identification of genes expressed during early oogenesis in medaka. Molecular Reproduction and Development 55: 31-36.

KATAGIRI, C. (1975). Properties of hatching enzyme from frog embryos. Journal of Experimental Zoology 193: 109-118.

KATAGIRI, C., IWAO, Y. and YOSHIZAKI, N. (1982). Participation of oviducal pars recta secretions in inducing the acrosome reaction and release of vitelline coat lysin in fertilizing toad sperm. Developmental Biology 94: 1-10.

KATAGIRI, C. (1987). Role of oviducal secretions in mediating gamete fusion in anuran amphibians. Zoological Science 4: 1-14.

KATAGIRI, C., MAEDA, R., YAMASHIKA, C., MITA, K., SARGENT, T.D. and YASUMASU, S. (1997). Molecular cloning of Xenopus hatching enzyme and its specific expression in hatching gland cells. International Journal of Develop mental Biology 41: 19-25.

KILLICK, R., LEGAN, P.K., MALENCZAK, C. and RICHARDSON, G.P. (1995). Molecular-cloning of chick beta-tectorin, an extracellular-matrix molecule of the inner-ear. Journal of Cell Biology 129: 535-547.

KUBO, H., KAWANO, T., TSUBUKI, S., KAWASHIMA, S., KATAGIRI, C. and SUZUKI, A. (1997). A major glycoprotein of Xenopus egg vitelline envelope, gp41, is a frog homolog of mammalian ZP3. Development Growth \& Differentiation 39: 405-417.

KUBO, $\mathrm{H}$., MATSUSHITA, $\mathrm{R}$., KOTANI, $\mathrm{M}$., KAWASAKI, $\mathrm{H}$., SAIDO, T.C., KAWASHIMA, S., KATGIRI, C. and SUZUKI, A. (1999). Molecular basis for oviductin-mediated processing from gp43 to gp41, the predominant glycoproteins of Xenopus egg envelopes. Developmental Genetics 25: 123-129.

KUBO, H., KAWANO, T., TSUBUKI, S., KOTANI, M., KAWASAKI, H. and KAWASHIMA, S. (2000). Egg envelope glycoprotein gp37 as a Xenopus homolog of mammalian ZP1, based on cDNA cloning. Development Growth \& Differentiation 42: 419-427.

KUDO, K., YONEZAWA, N., KATSUMATA, T., AOKI, H. and NAKANO, M. (1998). Localization of carbohydrate chains of pig sperm ligand in the glycoprotein ZPB of egg zona pellucida. European Journal of Biochemistry 252: 492-499.

KUPFFER, C. (1882). Ueber aktive betheiligung des dotters am befruchtungsakte bei Bufo variabilis and vulgaris. Sitzungsb. d. math. -physik Classed. k. b. Akad. d. Wiss. zu Munchen 12: 608-618.

LARABELL, C.A. and CHANDLER, D.E. (1988). The extracellular-matrix of xenopuslaevis eggs - a quick-freeze, deep-etch analysis of its modification at fertilization. Journal of Cell Biology 107: 731-741.

LARABELL, C.A. and CHANDLER, D.E. (1989). Quick-freeze, deep-etch, rotaryshadow views of the extracellular-matrix and cortical cytoskeleton of xenopuslaevis eggs. Journal of Electron Microscopy Technique 13: 228-243.

LARABELL, C.A. and CHANDLER, D.E. (1990). Stepwise transformation of the vitelline envelope of xenopus eggs at activation - a quick-freeze, deep-etch analysis. Developmental Biology 139: 263-268.

LEGAN, P.K., RAU, A., KEEN, J.N. and RICHARDSON, G.P. (1997). The mouse tectorins - modular matrix proteins of the inner ear homologous to components of the sperm-egg adhesion system. Journal of Biological Chemistry 272: 87918801.

LINDSAY, L.L. and HEDRICK, J.L. (1989). Proteases released from xenopuslaevis eggs at activation and their role in envelope conversion. Developmental Biology 135: 202-211.

LINDSAY, L.L., LARABELL, C.A. and HEDRICK, J.L. (1992). Localization of a chymotrypsin-like protease to the perivitelline space of xenopus-laevis eggs. Developmental Biology 154: 433-436.

LINDSAY, L.L. and HEDRICK, J.L. (1995). Isolation and characterization of ovochymase, a chymotrypsin-like protease released during xenopus-laevis egg activation. Developmental Biology 167: 513-516.

LINDSAY, L.L., WIEDUWILT, M.J. and HEDRICK, J.L. (1999a). Oviductin, the Xenopus laevis oviductal protease that processes egg envelope glycoprotein gp43, increases sperm binding to envelopes, and is translated as part of an unusual mosaic protein composed of two protease and several cub domains. Biology of Reproduction 60: 989-995.

LINDSAY, L.L., YANG, J.C. and HEDRICK, J.L. (1999b). Ovochymase, a Xenopus laevis egg extracellular protease, is translated as part of an unusual polyprotease. Proceedings of the National Academy of Sciences of the United States of America 96: 11253-11258.

LINDSAY, L.L., WALLACE, M.A. and HEDRICK, J.L. (2001). A hatching enzyme substrate in the Xenopus laevis egg envelope is a high molecular weight ZPA homolog. Development Growth \& Differentiation 43: 305-313.

LINDSAY, L.L. and HEDRICK, J.L. (2004). Proteolysis of Xenopus laevis egg envelope ZPA triggers envelope hardening. Biochemical and Biophysical Research Communications 324: 648-654.

LLANOS, R.J., BARRERA, D., VALZ-GIANINET, J.N. and MICELI, D.C. (2006) Oviductal protease and trypsin treatment enhance sperm-envelope interaction in Bufo arenarum coelomic eggs. Journal of Experimental Zoology Part $A$. Comparative Experimental Biology 305A: 872-882.

MARIANO, M.I. and CABADA, M.O. (1978). Modification of the vitelline envelope of coelomic Bufo arenarum oocytes by products of the cortical granules. Rev. Microsc. Electr. 5: 50-51.

MARIANO, M.I., DE MARTIN, M.G. and PISANO, E. (1984). Morphological modifications of oocyte vitelline envelope from Bufo arenarum during different functional states. Development, Growth \& Differentiation 26: 33-42.

MARTINEZ, M.L. and CABADA, M.O. (1996). Assessment of the acrosome reac tion in Bufo arenarum spermatozoa by immunostaining: Comparison with other methods. Zygote 4: 181-190.

MCCAULEY, T.C., BUHI, W.C., WU, G.M., MAO, J., CAAMANO, J.N., DIDION, B.A. and DAY, B.N. (2003). Oviduct-specific glycoprotein modulates spermzona binding and improves efficiency of porcine fertilization in vitro. Biology of Reproduction 69: 828-834.

MENINO, A.R. and WRIGHT, R.W. (1979). Characterization of porcine oocyte zonae pellucidae by polyacrylamide-gel electrophoresis. Proceedings of the Society for Experimental Biology and Medicine 160: 449-452.

MICELI, D.C., FERNANDEZ, S.N., RAISMAN, J.S. and BARBIERI, F.D. (1978). Trypsin-like oviducal proteinase involved in bufo-arenarum fertilization. Journal of Embryology and Experimental Morphology 48: 79-91.

MICELI, D.C., FERNANDEZ, S.N., MANSILLA, Z.C. and CABADA, M.O. (1987) New evidence of anuran oviducal pars recta involvement on gamete interaction. Journal of Experimental Zoology 244: 125-132.

MICHELMANN, H.W., RATH, D., TOPFER-PETERSEN, E. and SCHWARTZ, P. (2007). Structural and functional events on the porcine zona pellucida during maturation, fertilization and embryonic development: A scanning electron microscopy analysis. Reproduction in Domestic Animals 42: 594-602.

MILLER, D.J., GONG, X.H., DECKER, G. and SHUR, B.D. (1993). Egg cortical granule $\mathrm{N}$-acetylglucosaminidase is required for the mouse zona block to polyspermy. Journal of Cell Biology 123: 1431-1440.

MOLLER, C.C. and WASSARMAN, P.M. (1989). Characterization of a proteinase that cleaves zona pellucida glycoprotein-ZP2 following activation of mouse eggs. Developmental Biology 132: 103-112.

MONNE, M., HAN, L. and JOVINE, L. (2006). Tracking down the ZP domain: From the mammalian zona pellucida to the molluscan vitelline envelope. Seminars in Reproductive Medicine 24: 204-216.

MORGAN, T.H. (1897). The Development of the Frog's Egg: An Introduction to Experimental Embryology. The MacMillan Company, New York.

MORI, E., TAKASAKI, S., HEDRICK, J.L., WARDRIP, N.J., MORI, T. and KOBATA, A. (1991). Neutral oligosaccharide structures linked to asparagines of porcine zona-pellucida glycoproteins. Biochemistry 30: 2078-2087.

MORI, E., HEDRICK, J.L., WARDRIP, N.J., MORI, T. and TAKASAKI, S. (1998) Occurrence of reducing terminal $\mathrm{N}$-acetylglucosamine 3-sulfate and fucosylated outer chains in acidic $\mathrm{N}$-glycans of porcine zona pellucida glycoproteins. Glycoconjugate Journal15: 447-456.

NEEDHAM, J. (1963). Hatching and birth. In: Chemical embryology. New York, pp. 1595-1605.

NEWPORT, G. (1851). On the impregnation of the ovum in the amphibia. Philosophical Transactions of the Royal Society, London 141: 169-242.

NEWPORT, G. (1853). On the impregnation of the ovum in amphibia. And on the direct agency of the spermatozoon. Philosophical Transactions of the Royal Society of London 143: 233-290.

NEWPORT, G. and ELLIS, G.V. (1854). Researches on the impregnation of the ovum in amphibia; and on the early stages of development of the embryo. Philosophical Transactions of the Royal Society of London 144: 229-244.

NIEUWKOOP, P.D. and FABER, J. (1956). Normal table of Xenopus laevis (daudin). North-Holland Publishing Company, Amsterdam. 
NIKAS, G., PARASCHOS, T., PSYCHOYOS, A. and HANDYSIDE, A.H. (1994). The zona reaction in human oocytes as seen with scanning electron microscopy. Human Reproduction (Oxford) 9: 2135-2138.

NISHIHARA, T. and HEDRICK, J.L. (1977). Molecular mechanism for envelope elevation at fertilization. Federation Proceedings 36: 811.

NISHIHARA, T., GERTON, G.L. and HEDRICK, J.L. (1983). Radioiodination studies of the envelopes from xenopus-laevis eggs. Journal of Cellular Biochemistry 22: 235-244.

NISHIHARA, T., WYRICK, R.E., WORKING, P.K., CHEN, Y.H. and HEDRICK, J.L. (1986). Isolation and characterization of a lectin from the cortical granules of xenopus-laevis eggs. Biochemistry 25: 6013-6020.

NOGUCHI, S., HATANAKA, Y., TOBITA, T. and NAKANO, M. (1992). Structuralanalysis of the $\mathrm{N}$-linked carbohydrate chains of the 55-kda glycoprotein family (pZP3) from porcine zona-pellucida. European Journal of Biochemistry 204: 1089-1100.

OKUMURA, H., KOHNO, Y., IWATA, Y., MORI, H., AOKI, N., SATO, C., KITAJIMA K., NADANO, D. and MATSUDA, T. (2004). A newly identified zona pellucida glycoprotein, ZPD, and dimeric ZP1 of chicken egg envelope are involved in sperm activation on sperm-egg interaction. Biochemical Journa/384: 191-199.

OKUMURA, H., OKAJIMA, T., NADANO, D. and MATSUDA, T. (2007). Association of chicken zona pellucdia glycoprotein (ZP) b1 with ZPC induces formation of ZPB1-ZPC fibrous aggregates containing disulfide-bridged ZPB1 dimer. Biochemical and Biophysical Research Communications 364: 682-688.

OMATA, S. and KATAGIRI, C. (1996). Involvement of carbohydrate moieties of the toad egg vitelline coat in binding with fertilizing sperm. Development Growth \& Differentiation 38: 663-672.

OTERINO, J., TORANZO, G.S., ZELARAYAN, L., AJMAT, M.T., BONILLA, F. and BpHLER, M.I. (2006). Behavior of the vitelline envelope of Bufo arenarum oocytes matured in vitro in blockade of polyspermy. Zygote 14: 97-106.

PEARSE, A.G.E. (1968). The history of histochemistry. In: Histochemistry: Theoretical and Applied. Little, Brown, \& Company, Boston, pp. 1-12.

PEAVY, T.R. and CARROLL, E.J. (1993). The primary egg envelope of the anuran Lepidobatrachus-laevis - physicochemical and macromolecular alterations during development. Development Growth \& Differentiation 35: 447-460.

PRODY, G.A., GREVE, L.C. and HEDRICK, J.L. (1983). N-acetyl-beta-Dglucosaminidase activity in cortical granules - characterization and function. Journal of Cell Biology 97: A29-A29.

RAISMAN, J.S., MARIANO, M.I. and CABADA, M.O. (1977). Effect of trypsininhibitors and Concanavalin a on Bufo-arenarum fertilization. Development Growth \& Differentiation 19: 119-123.

RAISMAN, J.S., DECUNIO, R.W., CABADA, M.O., DELPINO, E.J. and MARIANO, M.I. (1980). Acrosome breakdown in Leptodactylus-chaquensis (amphibia, anura) spermatozoa. Development Growth \& Differentiation 22: 289-297.

RATH, D., TOPFER-PETERSEN, E., MICHELMANN, H.W., SCHWARTZ, P. and EBELING, S. (2005). Zona pellucida characteristics and sperm-binding patterns of in vivo and in vitro produced porcine oocytes inseminated with differently prepared spermatozoa. Theriogenology 63: 352-362.

RUGH, R. (1962). Experimentalembryology: Techniques and procedures. Burgess Publishing Company, Minneapolis.

SACCO, A.G., YUREWICZ, E.C., SUBRAMANIAN, M.G. and MATZAT, P.D. (1989). Porcine zona pellucida - association of sperm receptor activity with the alpha-glycoprotein component of the $\mathrm{mr}=55,000$ family. Biology of Reproduction 41: 523-532.

SASANAMI, T., OHTSUKI, M., ISHIGURO, T., MATSUSHIMA, K., HIYAMA, G., KANSAKU, N., DOI, Y. and MORI, M. (2006). Zona pellucida domain of ZPB1 controls specific binding of ZPB1 and ZPC in japanese quail (coturnix japonica). Cells Tissues Organs 183: 41-52.

SMART. (2007). Simple modular architecture research tool. Http://smart.Emblheidelberg.De/ accession number sm00042.

SPARGO, S.C. and HOPE, R.M. (2003). Evolution and nomenclature of the zona pellucida gene family. Biology of Reproduction 68: 358-362.

SUTOVSKY, P., MANANDHAR, G., MCCAULEY, T.C., CAAMANO, J.N., SUTOVSKY, M. and THOMPSON, W.E. (2004). Proteasomal interference prevents zona pellucida penetration and fertilization in mammals. Biology of Reproduction 71: 1625-1637.
SUZUKI, H., YANG, X. and FOOTE, R.H. (1994). Surface alterations of the bovine oocyte and its investments during and after maturation and fertilization in vitro. Molecular Reproduction and Development 38: 421-430.

TAKAMUNE, K. and KATAGIRI, C. (1987). The properties of the oviducal pars recta protease which mediates gamete interaction by affecting the vitelline coat of a toad egg. Development Growth \& Differentiation 29: 193-203.

TAKAMUNE, K., LINDSAY, L., HEDRICK, J.L. and KATAGIRI, C. (1987). Comparative-studies of bufo and xenopus vitelline coat molecular-transformations induced by homologous and heterologous oviducal pars recta proteases. Journal of Experimental Zoology 244: 145-150.

TIAN, J.D., GONG, H., THOMSEN, G.H. and LENNARZ, W.J. (1996). The 69 and $64 \mathrm{kda}$ glycoproteins in the vitelline envelope of Xenopus eggs mediate spermegg binding during fertilization. Molecular Biology of the Cel/7: 2807-2807.

TIAN, J.D., GONG, H., THOMSEN, G.H. and LENNARZ, W.J. (1997). Gamete interactions in Xenopus laevis: Identification of sperm binding glycoproteins in the egg vitelline envelope. Journal of Cell Biology 136: 1099-1108.

TIAN, J.D., GONG, H. and LENNARZ, W.J. (1999). Xenopus laevis sperm receptor gp69/64 glycoprotein is a homolog of the mammalian sperm receptor ZP2. Proceedings of the National Academy of Sciences of the United States of America 96: 829-834.

UEDA, Y., YOSHIZAKI, N. and IWAO, Y. (2002). Acrosome reaction in sperm of the frog, Xenopus laevis: Its detection and induction by oviductal pars recta secretion. Developmental Biology 243: 55-64.

UEDA, Y., KUBO, H. and IWAO, Y. (2003). Characterization of the acrosome reaction-inducing substance in Xenopus (ARISX) secreted from the oviductal pars recta onto the vitelline envelope. Developmental Biology 264: 289-298.

UEDA, Y., IMAIZUMI, C., KUBO, H., SATO, K.I., FUKAMI, Y. and IWAO, Y. (2007). Analysis of terminal sugar moieties and species-specificities of acrosome reaction-inducing substance in Xenopus (ARISX). Development Growth \& Differentiation 49: 591-601.

URCH, U.A. and HEDRICK, J.L. (1981a). The hatching enzyme from xenopuslaevis - limited proteolysis of the fertilization envelope. Journal of Supramolecular Structure and Cellular Biochemistry 15: 111-117.

URCH, U.A. and HEDRICK, J.L. (1981b). Isolation and characterization of the hatching enzyme from the amphibian, xenopus-laevis. Archives of Biochemistry and Biophysics 206: 424-431.

VO, L.H. and HEDRICK, J.L. (2000). Independent and hetero-oligomeric-dependent sperm binding to egg envelope glycoprotein ZPC in Xenopus laevis. Biology of Reproduction 62: 766-774.

VO, L.H., YEN, T.Y., MACHER, B.A. and HEDRICK, J.L. (2003). Identification of the ZPC oligosaccharide ligand involved in sperm binding and the glycan structures of Xenopus laevis vitelline envelope glycoproteins. Biology of Reproduction 69: 1822-1830.

VON WITZENDORFF, D., EKHLASI-HUNDRIESER, M., DOSTALOVA, Z., RESCH, M., RATH, D., MICHELMANN, H.W. and TOPFER-PETERSEN, E. (2005). Analysis of $\mathrm{N}$-linked glycans of porcine zona pellucida glycoprotein ZPA by Maldi-tof MS: A contribution to understanding zona pellucida structure. Glycobiology 15: 475-488.

WANG, W.H., DAY, B.N. and WU, G.M. (2003). How does polyspermy happen in mammalian oocytes? Microscopy Research and Technique 61: 335-341.

WATANABE, A. and ONITAKE, K. (2002). The urodele egg-coat as the apparatus adapted for the internal fertilization. Zoological Science 19: 1341-1347.

WHITACRE, C.M., PERDIGON, G., FERNANDEZ, S.N. and MICELI, D.C. (1996) Role of oviductal pars recta extract on interspecific fertilization between anurans. Development Growth \& Differentiation 38: 203-207.

WOLF, D.P. and HEDRICK, J.L. (1971). Molecular approach to fertilization 3. Development of a bioassay for sperm capacitation. Developmental Biology25: 360-\&.

WOLF, D.P., NISHIHARA, T., WEST, D.M., WYRICK, R.E. and HEDRICK, J.L. (1976). Isolation, physicochemical properties, and macromolecular-composition of vitelline and fertilization envelopes from xenopus-laevis eggs. Biochemistry 15: 3671-3678.

WOLF, D.P. (1981). The mammalian egg's block to polyspermy. In: MASTRONIANNI, L. and BIGGERS, J.D., Eds., Fertilization and embryonic development in vitro. Plenum Publishing, New York, pp. 183-197.

WONG, J.L. and WESSEL, G.M. (2006). Defending the zygote: Search for the 
ancestral animal block to polyspermy. Current Topics in Developmental Biology 72: 1-151.

WYRICK, R.E., NISHIHARA, T. and HEDRICK, J.L. (1974a). Fertilization envelope formation by glycoprotein agglutination and block to polyspermy in xenopuslaevis. Federation Proceedings 33: 1453-1453.

WYRICK, R.E., NISHIHARA, T. and HEDRICK, J.L. (1974b). Agglutination of jelly coat and cortical granule components and the block to polyspermy in the amphibian Xenopus laevis. Proceedings of the National Academy of Sciences USA 71: 2067-2071.

YAMAGUCHI, S., HEDRICK, J.L. and KATAGIRI, C. (1989). The synthesis and localization of envelope glycoproteins in oocytes of xenopus-laevis using immunocytochemical methods. Development Growth \& Differentiation 31: 8594.

YAMASAKI, H., TAKAMUNE, K. and KATAGIRI, C. (1988). Classification, inhibition, and specificity studies of the vitelline coat lysin from toad sperm. Gamete Research 20: 287-300.

YAMASAKI, H., KATAGIRI, C. and YOSHIZAKI, N. (1990). Selective degradation of specific components of fertilization coat and differentiation of hatching glandcells during the 2 phase hatching of bufo-japonicus embryos. Development Growth \& Differentiation 32: 65-72.

YANG, J.C. and HEDRICK, J.L. (1997). cDNA cloning and sequence analysis of the Xenopus laevis egg envelope glycoprotein gp43. Development Growth \& Differentiation 39: 457-467.

YI, Y.J., MANANDHAR, G., SUTOVSKY, M., LI, R., JONAKOVA, V., OKO, R., PARK, C.S., PRATHER, R.S. and SUTOVSKY, P. (2007). Ubiquitin c-terminal hydrolase-activity is involved in sperm acrosomal function and anti-polyspermy defense during porcine fertilization. Biology of Reproduction 77: 780-793.

YONEZAWA, N., AOKI, H., HATANAKA, Y. and NAKANO, M. (1995a). Involvement of $\mathrm{N}$-linked carbohydrate chains of pig zona-pellucida in sperm-egg binding. European Journal of Biochemistry 233: 35-41.

YONEZAWA, N., HATANAKA, Y., TAKEYAMA, H. and NAKANO, M. (1995b). Binding of pig sperm receptor in the zona-pellucida to the boar sperm acrosome. Journal of Reproduction and Fertility 103: 1-8.

YONEZAWA, N., FUKUI, N., KUDO, K. and NAKANO, M. (1999). Localization of neutral $\mathrm{N}$-linked carbohydrate chains in pig zona pellucida glycoprotein ZPC. European Journal of Biochemistry 260: 57-63.

YONEZAWA, N., AMARI, S., TAKAHASHI, K., IKEDA, K., IMAI, F.L., KANAI, S., KIKUCHI, K. and NAKANO, M. (2005). Participation of the nonreducing terminal beta-galactosyl residues of the neutral $\mathrm{N}$-linked carbohydrate chains of porcine zona pellucida glycoproteins in sperm-egg binding. Molecular Reproduction and Development 70: 222-227.

YOSHIZAKI, N. and KATAGIRI, C. (1975). Cellular basis for production and secretion of hatching enzyme by frog embryos. Journal of Experimental Zoology 192: 203-212.

YOSHIZAKI, N. (1978). Disintegration of vitelline coat during hatching process in frog. Journal of Experimental Zoology 203: 127-133.

YOSHIZAKI, N. and KATAGIRI, C. (1981). Oviducal contribution to alteration of the vitelline coat in the frog, Rana-japonica - an electron-microscopic study. Deve/opment Growth \& Differentiation 23: 495-506.

YOSHIZAKI, N. and KATAGIRI, C. (1982). Acrosome reaction in sperm of the toad, Bufo bufo japonicus. Gamete Research 6: 343-352.

YOSHIZAKI, N. (1991). Changes in surface ultrastructure and proteolytic activity of hatching gland-cells during development of Xenopus embryo. Zoological Science 8: 295-302.

YOSHIZAKI, N. and YAMASAKI, H. (1991). Morphological and biochemical-changes in the fertilization coat of Xenopus-laevis during the hatching process. Zoological Science 8: 303-308.

YUREWICZ, E.C., OLIPHANT, G. and HEDRICK, J.L. (1975). Macromolecularcomposition of Xenopus-laevis egg jelly coat. Biochemistry 14: 3101-3107.

YUREWICZ, E.C., SACCO, A.G. and SUBRAMANIAN, M.G. (1987). Structural characterization of the $\mathrm{mr}=55,000$ antigen (ZP3) of porcine oocyte zonapellucida - purification and characterization of alpha-glycoprotein and betaglycoprotein following digestion of lactosaminoglycan with endo-beta-galactosidase. Journal of Biological Chemistry 262: 564-571.

YUREWICZ, E.C., PACK, B.A. and SACCO, A.G. (1991). Isolation, composition, and biological-activity of sugar chains of porcine oocyte zona-pellucida 55kglycoproteins. Molecular Reproduction and Development 30: 126-134.

YUREWICZ, E.C., HIBLER, D., FONTENOT, G.K., SACCO, A.G. and HARRIS, J. (1993a). Nucleotide-sequence of cDNA-encoding ZP3-alpha, a sperm-binding glycoprotein from zona-pellucida of pig oocyte. Biochimica Et Biophysica Acta 1174: 211-214.

YUREWICZ, E.C., PACK, B.A., ARMANT, D.R. and SACCO, A.G. (1993b). Porcine zona-pellucida ZP3-alpha glycoprotein mediates binding of the biotin-labeled m(r)-55,000 family (ZP3) to boar sperm membrane-vesicles. Molecular Reproduction and Development 36: 382-389.

YUREWICZ, E.C., SACCO, A.G., GUPTA, S.K., XU, N.X. and GAGE, D.A. (1998). Hetero-oligomerization-dependent binding of pig oocyte zona pellucida glycoproteins ZPB and ZPC to boar sperm membrane vesicles. Journal of Biological Chemistry 273: 7488-7494.

\section{NOTE added in proof}

Some particularly relevant papers have been published since this review was submitted.

Goudet et al., analyzed and updated the phylogenetic relations of ZP genes from fish, frogs, chickens and mammals and the comparative nomenclature for ZP glycoproteins (Goudet et al., 2008). They proposed that there was a progressive loss of ZP genes and glycoproteins during the evolution of vertebrates. They suggested that the number and composition of glycoproteins in the ZP might affect taxon specific sperm$\mathrm{ZP}$ binding in mammals.

A sperm ZPA binding glycoprotein (ZPBP1) named SP38 or IAM38 was originally identified in pig sperm as an acrosomal protein. A second sperm ZP binding glycoprotein (ZPBP2) was identified in mice. Members of the sperm ZP binding glycoprotein gene family were cloned from mouse, human, chicken and Xenopus laevis and investigated regarding their biological roles using the knock mouse model (Lin et al., 2008). The ZPBP binding glycoproteins were found to be integral structural components involved in acrosome matrix compaction (ZPBP1) and interaction with the ZP during sperm penetration (ZPBP2). Xenopus laevis had only the gene for the ZPBP2 glycoprotein. The authors suggested that "..Xenopus may be an alternative mode/ organism system for future analysis of ZPBP functions during sperm penetration".

Familiari et al. published a review with the aim of integrating ultrastructural and molecular observations of the ZP during ovulation, fertilization, and preimplantation development (Familiari et al., 2008). Analyses and comparisons of the fine structures and organizations of $Z P$, including pig and human, were presented. The authors concluded that TEM and SEM observations "..support a morphological ultrastructural supramolecularmodel, more similar and comparable to molecularmodels (connected) with a glycoprotein network (lattice). "They concluded that there was a correlation between ZP structure (spongy versus compact or smooth), ZP function (sperm binding and penetration), and ZP age (oocyte, fertilized egg, embryo). They suggested a spongy or compact SEM appearance of the ZP may positively correlate with sperm-binding and penetration of the ZP whereas a smooth or compact structure may 
negatively correlate with sperm binding and penetration.

Sperm binding to the VE of dejellied Xenopus laevis eggs was investigated using trypsin and aminopeptidase $B$ protease inhibitors and synthetic protease substrates. Protease activities in isolated sperm membranes were also measured. From the results reported, it was suggested that "..proteases involved in binding to the vitelline envelope are on the sperm plasma membrane." (Kubo et al., 2008).

\section{Additional References}

FAMILIARI, G., HEYN, R., RELUCENTI, M., and SATHANANTHAN, H. (2008). Structural changes of the zona pellucida during fertilization and embryo development. Frontiers in Bioscience 13:6730-6751.

GOUDET, G., MUGNIER, S., CALLEBAUT, I., and MONGET, P. (2008). Phylogenetic analysis and identification of pseudogenes reveal a progressive loss of zona pellucida genes during evolution of vertebrates. Biology of Reproduction78:796806.

KUBO, H., KOTANI, M., YAMAMOTO, Y., and HAZATO, T. (2008). Involvement of sperm proteases in the binding of sperm to the vitelline envelope in Xenopus laevis. Zoological Science 25:80-87.

LIN, Y., ROY, A., YAN, W., BURNS, K.H., and MATZUK, M.M. (2007). Loss of zona pellucida binding proteins in the acrosomal matrix disrupts acrosome biogenesis and sperm morphogenesis. Molecular and Cellular Biology 27:6794-6805.

\section{Related, previously published Int. J. Dev. Biol. articles}

See our recent Special Issue Developmental Biology in Poland edited by Tarkowski, Maleszewski and Kloc at: http://www.ijdb.ehu.es/web/contents.php?vol=52\&issue=2-3

See our recent Special Issue Ear Development edited by Fernando Giraldez and Bernd Fritzsch at: http://www.ijdb.ehu.es/web/contents.php?vol=51\&issue=6-7

\section{Glycobiology of fertilization in the pig}

Edda Töpfer-Petersen, Mahnaz Ekhlasi-Hundrieser and Miroslava Tsolova Int. J. Dev. Biol. (2008) 52: 717-736

Experimental embryonic-somatic chimaerism in the sheep confirmed by random amplified polymorphic DNA assay Jolanta Karasiewicz, Mariusz Sacharczuk, Boguslaw Was, Andrzej Guszkiewicz, Maciej Korwin-Kossakowski, Maria Gorniewska, Ewa Szablisty and Jacek A. Modlinski

Int. J. Dev. Biol. (2008) 52: 315-322

\section{Animal reproduction biotechnology in Poland}

Zdzislaw Smorag, Lucyna Katska-Ksiazkiewicz, Maria Skrzyszowska, Jacek Jura, Barbara Gajda and Michal Bochenek

Int. J. Dev. Biol. (2008) 52: 151-155

Drosophila retinal pigment cell death is regulated in a position-dependent manner by a cell memory gene

Nicolas Dos-Santos, Thomas Rubin, Fabienne Chalvet, Pierre Gandille, Frederic Cremazy, Jacqueline Leroy, E. Boissonneau and Laurent Théodore

Int. J. Dev. Biol. (2008) 52: 21-31

CpZPC, a newt ZPC molecule, localizes to the inner surface of the egg envelope. Youko Makabe-Kobayashi, Etsuko Kudaira, Akihiko Watanabe and Kazuo Onitake Int. J. Dev. Biol. (2003) 47: 51-58

Developmental competence of immature pig oocytes under the influence of EGF, IGF-I, follicular fluid and gonadotropins during IVM-IVF processes.

M J Illera, P L Lorenzo, J C Illera and R M Petters

Int. J. Dev. Biol. (1998) 42: 1169-1172

Developmental competence of immature pig oocytes under the influence of EGF, IGF-I, follicular fluid and gonadotropins during IVM-IVF processes.

M J Illera, P L Lorenzo, J C Illera and R M Petters

Int. J. Dev. Biol. (1998) 42: 1169-1172

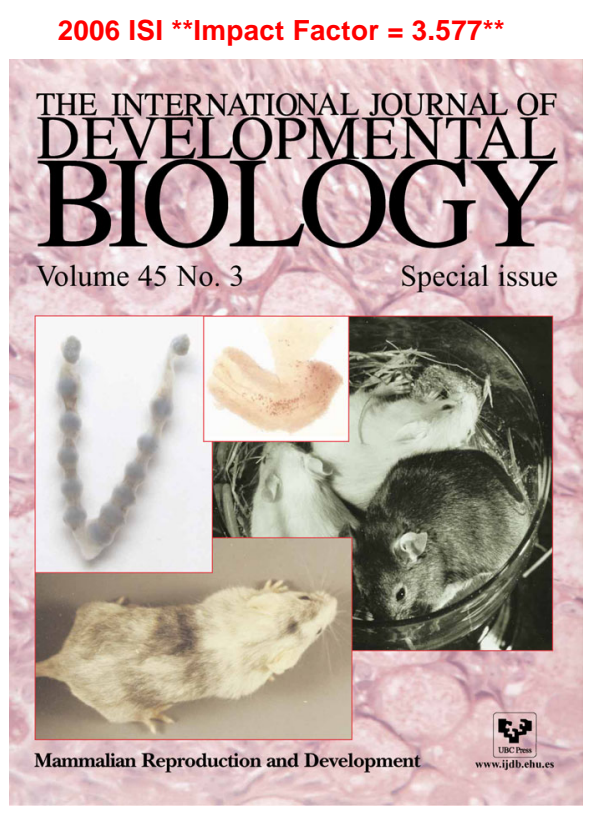

